\title{
MORG $1^{+/-}$mice are protected from histological renal damage and inflammation in a murine model of endotoxemia
}

Tzvetanka Bondeva ${ }^{1 \dagger}$, Claudia Schindler ${ }^{1,2+}$, Katrin Schindler ${ }^{1,2}$ and Gunter Wolf $f^{1 *}$

\begin{abstract}
Background: The MAPK-organizer 1 (MORG1) play a scaffold function in the MAPK and/or the PHD3 signalling paths. Recently, we reported that MORG1 $1^{+-}$mice are protected from renal injury induced by systemic hypoxia and acute renal ischemia-reperfusion injury via increased hypoxia-inducible factors (HIFs). Here, we explore whether MORG1 heterozygosity could attenuate renal injury in a murine model of lipopolysaccharide (LPS) induced endotoxemia.

Methods: Endotoxemia was induced in mice by an intraperitoneal (i.p) application of $5 \mathrm{mg} / \mathrm{kg}$ BW LPS. The renal damage was estimated by periodic acid Schiff's staining; renal injury was evaluated by detection of urinary and plasma levels of neutrophil gelatinase-associated lipocalin and albumin/creatinine ratio via ELISAs. Renal mRNA expression was assessed by real-time PCR, whereas the protein expression was determined by immunohistochemistry or Western blotting.

Results: LPS administration increased tubular injury, microalbuminuria, IL-6 plasma levels and renal TNF-a expression in $M O R G 1^{+/+}$mice. This was accompanied with enhanced infiltration of the inflammatory T-cells in renal tissue and activation of the NF-kB transcription factors. In contrast, endotoxemic MORG $1^{+/-}$showed significantly less tubular injury, reduced plasma IL-6 levels, significantly decreased renal TNF-a expression and T-cells infiltration. In support, the renal levels of activated caspase-3 were lower in endotoxemic MORG1 ${ }^{+/-}$mice compared with endotoxemic MORGI ${ }^{+/+}$mice. Interestingly, LPS application induced a significantly higher accumulation of renal HIF-2a in the kidneys of MORG1 ${ }^{+/-}$ mice than in wild-type mice, accompanied with a diminished phosphorylation of IKB- $\alpha$ and IKK $a, \beta$ and decreased iNOS mRNA in the renal tissues of the LPS-challenged $M O R G 1^{+/-}$mice, indicating an inhibition of the NF-KB transcriptional activation.
\end{abstract}

Conclusions: MORG1 heterozygosity protects against histological renal damage and shows anti-inflammatory effects in a murine endotoxemia model through modulation of HIF-2a stabilisation and/or simultaneous inhibition of the NF-KB signalling. Here, we show for the first time that MORG1 scaffold could represent the missing link between innate immunity and inflammation.

Keywords: Endotoxemia, MORG1, PHD3, HIF-2a, Renal injury, Inflammation

\footnotetext{
* Correspondence: GWolf@med.uni-jena.de

${ }^{\dagger}$ Equal contributors

${ }^{1}$ Department of Internal Medicine III, Jena University Hospital, Am Klinikum 1,

D-07740 Jena, Germany

Full list of author information is available at the end of the article
} 


\section{Background}

Sepsis is a systemic response of the body to host infections. Septic conditions are often clinically difficult to diagnose and contribute to higher morbidity and mortality rates in ICUs world-wide [1]. Increased mortality due to sepsis is oft caused by bacterial infections and the lipid A-containing lipopolysaccharide (LPS), a component of the bacterial wall of the gram-negative bacteria, is a major player in the pathogenesis the of gram-negative sepsis [2]. The application of animal models have demonstrated that LPSinduced endotoxemia provokes tissue inflammation by a massive release of the inflammatory mediators as inflammatory cytokines and can lead to acute kidney injury in mice [3]. LPS treatment induced in animal models caused a systemic hypotension and organ dysfunction similar to what occurs in clinical sepsis [4], thus providing insight into the understanding of the pathogenesis of the acute renal injury. Recent studies have shown that LPS can activate the hypoxia-inducible transcription factor- 1 alpha (HIF-1 $\alpha$ ) under normoxic conditions [5]. The pharmacological activation of HIF- $1 \alpha$ through inhibition of HIFprolyl-hydroxylases (PHDs) [6] or administration of erythropoietin, a HIFs target gene, improved renal function and reduced acute kidney injury in endotoxemic mice [7] as well as in mice suffering from polymicrobial sepsis [8]. Recently, we reported that preconditional suppression of PHDs by application of 3,4-dihydroxybezoate (3,4-DHB), a non-specific PHDs inhibitor, was renoprotective in two murine septic models [9]. However, this effect was mainly localised to the kidney, we did not observe a protective systemic effect in the survival study [10]. The discovery of the MAPK-organizer 1 (MORG1), a molecular scaffold for multiple proteins of the MAPK cascade [11] and a binding partner of the HIF-prolyl hydroxylase domain containing protein 3 (PHD3) [11] opens a new opportunity to study the role of pre-elevated HIFs level and its function in AKI due to sepsis and inflammation. Genetic manipulation of MORG1 expression has revealed that $M O R G 1^{-1-}$ mice exhibit embryonic lethality, whereas MORG1 $1^{+/}$mice did not show phenotypic differences with the wild-type mice. Moreover, we found that $M O R G 1^{+/-}$animals are protected from renal injury in a murine model of ischemia/reperfusion due to increased HIF-1, $2 \alpha$ expression and stabilisation [12]. In normoxia HIFs are hydroxylated by PHDs followed by ubiquitination and proteasomal degradation [13]. Reduced oxygen supply in the cells is detected by PHDs and this inhibits their HIF-prolylhydroxylase activity, resulting in HIF stabilisation and transcriptional activation. Recent research from our lab has also shown that reduced expression of MORG1 could contribute to cellular adaptation to ischemic/ hypoxic conditions through the cellular binding partner(s) PHD3/HIFs. In a murine hypoxia model $M O R G 1^{+/-}$mice were protected from systemic hypoxia- dependent renal injury due to an enhanced stability of HIF-1,2 $\alpha$ and/or a reduced TNF- $\alpha$ expression in a PHD3/ MORG1 dependent manner [14] compared to the MORG1 ${ }^{+/+}$mice which developed overt renal damage and inflammation in an animal model of systemic hypoxia [14]. Thus, we hypothesised that MORG1 heterozygosity could attenuate kidney damage and inflammation, thus representing an important tool to gain insight into the cellular mechanisms of renal injury and inflammation related hypoxia in a well-established murine model of LPS-induced endotoxemia.

\section{Methods}

Animal treatment and endotoxemia induction

The animal experiments were performed according to the guidelines set by the local Animal Committee of the State of Thuringia application (file numbers 02-023/10 and 02-023/11). The animal experiments were approved by the Animal Committee of the State of Thuringia (Thueringer Landesamt fuer Lebensmittelsicherheits und Verbraucherschutz Abt. 2, Gesundheitlicher Verbraucherschutz, Veterinaerwesen, Pharmazie, Bad Langensalza, Germany) with files numbers 02-023/10 and $02-023 / 11$ and were carried out in accordance to the National Institute of Health Guidelines for the Care and Use of Laboratory Animals (8th edition; available online: https://www.ncbi.nlm.nih.gov/books/NBK54050/) and to the European Community Council Directive for the Care and Use of Laboratory Animals (Directive 2010/63/EU; http://ec.europa.eu/environment/chemicals/ lab_animals/legislation_en.htm). The study was performed on wild-type mice C57BL/6 J (Jackson Laboratories, Main, USA obtained from Charles River Laboratories, Sulzfeld, Germany) and MORG1 heterozygous animals. The $M O R G 1^{+/-}$mice were generated as described in [12] and were backcrossed for more than 12 generation to mice with C57BL/6 J genetic background. 12-16 weeks old $M O R G 1^{+/+}$and MORG1 ${ }^{+/-}$male mice, weighting 20-25 g were used in the study and received a standard diet and free access to tap water. 18 wild-type mice $\left(M O R G 1^{+/+}\right)$ and 18 heterozygous MORG1 $\left(M O R G 1^{+/-}\right)$animals were used for the study and were randomly separated into 4 groups ( $n=9$ per group) see below. All animals were bred and maintained at the "Central Experimental Animal Facilities (ZET)" at Friedrich Schiller University Hospital, Jena, Germany with regular 12/12 h light/ dark cycles and $23 \pm 1{ }^{\circ} \mathrm{C}$ room temperature. The mice used in the experimental procedure were age and sex matched and were randomly separated into the experimental groups and either received intraperitoneal injection (i.p.) of $0.9 \% \mathrm{NaCl}$ $\left(M O R G 1^{+/+}\right.$and $M O R G 1^{+/-}$control group) for $24 \mathrm{~h}$ or an i.p. application of $5 \mathrm{mg} / \mathrm{kg} \mathrm{BW}$ lipopolysaccharides from E. coli O111:B4 (LPS) to induce endotoxemia, purchased 
from Sigma-Aldrich Chemie $\mathrm{GmbH}$, (Taufkirchen, Germany) for $24 \mathrm{~h}\left(\mathrm{MORG1}^{+/+}\right.$and $\mathrm{MORG1}^{+/-} \mathrm{LPS}$ group). The experimental treatments were performed according to the approved experimental LPS dose and procedure from the Animal Committee of the State of Thuringia, Bad Langensalza, Germany (file 02-023/ 10). Briefly, the LPS dose of $5 \mathrm{mg} / \mathrm{kg} \mathrm{BW}$ was freshly prepared and injected once by i.p. application + a vehicle solution of $25 \mu \mathrm{l} / \mathrm{g}$ BW of $0.9 \% \mathrm{NaCl}$, which was applied by subcutaneous injection. The treatments were performed under a short isofluran anaesthesia using a standard procedure described elsewhere [15-17]. The clinical status of the animals was evaluated every $4 \mathrm{~h}$ by applying a Clinical Severity Score (CSS) as described previously [18]. The score uses the following parameters and ranges from 1 to 4 for each of them: spontaneous activity; reaction to exogenous stimuli and posture [18]. $24 \mathrm{~h}$ after treatments the mice were deep anesthetised with isofluran before being sacrificed by cervical dislocation as approved by the Animal Committee of the State of Thuringia and described in the European Community Council Directive for the Care and Use of Laboratory Animals (Directive 2010/63/EU; ANNEX IV (3.Table).The kidneys were collected and paraffin embedded or kept frozen at $-80{ }^{\circ} \mathrm{C}$ for further analysis. Blood samples were collected for blood plasma isolation and analysis. The collected urine samples were also stored at $-80^{\circ} \mathrm{C}$ until analysed.

\section{Survival analysis}

The systemic effect of endotoxemia was investigated by survival studies as described previously [15]. The survival study was approved from the Animal Committee of the State of Thuringia (file number 02-023/11). The survival analyses were carried out because there are so far no data about the $M O R G 1^{+/-}$mice sensitivity to lipopolysaccharide exposure. The mice were randomly separated into experimental groups as described above. Each group contained 10 animals and received a single dose of $0.9 \% \mathrm{NaCl}$ or LPS. The LPS application was performed as described above. During the $72 \mathrm{~h}$ survival analyses the mice were weighed once daily and the clinical well-being of the animals was estimated by the application of CSS [18], which was evaluated every $4 \mathrm{~h}$. The CSS was approved by the Animal Committee of the State of Thuringia. Subsequently the animal's survival was monitored and recorded every $6 \mathrm{~h}$ over a $72 \mathrm{~h}$ period and the mice had a free access to water and standard rodent food. The animals who survived the analyses were deep anesthetised with isofluran before being sacrificed by cervical dislocation, a standard procedure, in accordance to the approved protocol by the Animal Committee of the State of Thuringia (file number 02-023/11).

\section{Evaluation of kidney function and morphology}

The kidney functional parameter or renal morphology and tubular injury were performed on kidney harvested $24 \mathrm{~h}$ post induction of endotoxemia by LPS administration or application of saline solution in the corresponding experimental groups. In order to calculate the urinary albumin-creatinine-ratio (ACR) during the corresponding treatment, the animals were kept in metabolic cages (Techniplast, Hohenpeißenberg, Germany) and $24 \mathrm{~h}$ urine was collected. The urinary levels of creatinine and albumin were determined by enzyme-linked immunosorbent assay (ELISA), respectively from Cayman Chemical Company (Tallinn, Estland) and CellTrend $\mathrm{GmbH}$ (Luckenwalde, Germany). The urinary concentration of neutrophil gelatinase-associated lipocalin (NGAL) of the corresponding treatment, we also measured in $24 \mathrm{~h}$ collected urine. The urinary and plasma levels of NGAL were detected by mouse NGAL ELISA kit, purchased from BioPorto Diagnostics, Gentofte, Denmark. The assay was performed according to manufacturer instructions. The limit of the sample detection was $75 \mathrm{pg} / \mathrm{ml}$ and the assay range was $10-1000 \mathrm{pg} / \mathrm{ml}$ NGAL. The plasma levels of creatinine (Cre) and blood urea nitrogen (BUN) were measured in blood plasma $24 \mathrm{~h}$ post LPS application or saline injection in all experimental groups by colorimetric chip assay on clinical chemical analyzer (Fuji DRI-CHEM 3500i, Fujifilm, Dusseldorf, Germany). The Cre and BUN concentrations are expressed in $\mathrm{mg} / \mathrm{dl}$. Tubular damage was estimated by periodic acid Schiff-reaction (PAS) performed on $2 \mu \mathrm{m}$ paraffin kidney sections using a PAS staining kit (Baacklab, Schwerin, Germany). The staining was evaluated using an Axioplan microscope and AxioVision Rel. 4.6. software (Zeiss, Jena, Germany). The tubular damage was estimated by scoring system where 0 represent no damage and 5 corresponded to more than $90 \%$ injured proximal tubule. We also investigated the proximal tubular cells injury based on the positivity of immunohistological detection of Kidney injury molecule 1 (KIM1) in renal tissue in all experimental groups. The number of damaged (positively stained) tubuli per kidney section was counted and the average number is graphically presented.

\section{Assessment of protein expression in renal tissue by immunohistochemistry}

The kidneys were fixed in 10\% neutral-buffered formalin and were paraffin embedded. For immunohistological analyses, we used $4 \mu \mathrm{m}$ paraffin kidney sections with heat-induced antigen retrieval, as described elsewhere [19]. For immunohistochemistry the kidney sections were blocked with $5 \%$ BSA for $1 \mathrm{~h}$ at room temperature, followed by incubation with the primary antibodies overnight at $4{ }^{\circ} \mathrm{C}$. The following primary antibodies were used: goat-polyclonal antibody anti-HIF- $2 \alpha$ purchased 
from R\&D Systems (Wiesbaden, Germany) and used in 1:200 dilution, an anti-CD3 antibody (1:100 dilution) was obtained from Dianova GmbH (Hamburg, Germany), an anti-PHD3 antibody (1:100 dilution) was from Santa Cruz Biotechnology (Heidelberg, Germany), and anti- KIM1 antibody (1:1000 dilution) was purchased from Cloud One Corp. (Houston, TX, USA). The corresponding secondary antibodies, HRP-conjugated (1:500 dilution), were purchased from KPL Inc. (Gaithersburg, MD, USA). Peroxidase substrates were either 3-amino-9-ethylcarbazole (AEC) or diaminobenzidine (DAB) as appropriate, both purchased from (Vector Laboratories Inc., Burlingame, CA, USA). When appropriate the nuclei were counter-stained with hematoxylin (Vector Laboratories Inc.) for $2 \mathrm{~min}$. The stains were mounted and microscopic analyses were performed by Axioplan microscope and AxioVision Rel. 4.6. software (Zeiss, Jena, Germany). A minimum of 4-6 animals per experimental group were investigated. Routinely, the staining was analysed "blind" from a person unaware of the experimental protocol via a semi-quantitative scoring method (for detection of CD3 positive cells) to estimate the staining intensity as previously reported [20] or the number of detectable positively stained cells per field were counted by Image software using a cell counting analyses and presented graphically as mean \pm SEM.

\section{Assessment of protein expression in renal tissue by western blot analyses}

For protein analyses the kidneys were extracted $24 \mathrm{~h}$ following LPS i.p. application or saline solution and the protein expression was evaluated. Assessment of protein was performed in kidneys homogenised in complete lysis $\mathrm{M}$ supplemented with inhibitors (Roche, Mannheim, Germany) and $1 \mathrm{mM}$ sodium-orthovanadate. Routinely 3 to 4 animals per group were randomly selected for Western blot analyses. The lysates were vortexed, kept on ice for $15 \mathrm{~min}$ and centrifuged at $14,000 \mathrm{rpm}$ for $20 \mathrm{~min}$ at $4{ }^{\circ} \mathrm{C}$. The supernatant was then used for the further analysis. To evaluate the protein expression $12 \%$ or $15 \%$ SDS-PAGE were performed, followed by transfer of the gels onto a PVDF membrane. The detection of the protein was performed by ImageQuantTM LAS 4000 biomolecular imager system (GE Healthcare, Upsala, Sweden) via ECL- visualisation. The following antibodies were used for protein detection:

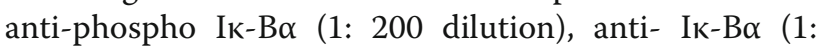
200 dilution), anti-phospho-IKK $\alpha, \beta$ (Ser 180, Ser181) (1: 200), anti-IKK $\alpha$ (1: 200), anti-vinculin (1: 2000 dilution), anti-TNF $\alpha$ (1: 200 dilution), anti-PCNA (proliferating cell nuclear antigen) (1: 500 dilution), anti-NF- $\mathrm{kB}$ (1:200). All antibodies were purchased from Santa Cruz Biotechnology (Heidelberg, Germany). The expression of caspase-3 was detected by anti-caspase- 3 antibody (1:1000 dilution) purchased from abcam, Cambridge, UK. The assessment of the nuclear NF- $\mathrm{kB}$ levels was performed by preparation of kidney nuclear extracts by the use of ProteoExtract ${ }^{\circ}$ Subcellular Proteome Extraction kit (Merck, Darmstadt, Germany). The expression of the proteins was subjected to densitometry measurement using ImageJ software.

RNA isolation, reverse transcription and real - time PCR

Renal expression of the genes of interest was analysed $24 \mathrm{~h}$ post endotoxin administration or saline injection. Renal tissue was homogenized using a SpeedMill P12 homogenizer (Analytik Jena Bio Solutions, Jena, Germany) and total RNA was isolated using the RNeasy kit (Qiagen, Hilden, Germany) according to the manufacturer's instructions. The synthesis of cDNA was performed routinely from $1 \mu \mathrm{g}$ of total RNA using the M-MLV Reverse Transcription system (Invitrogen Life Technologies, Darmstadt, Germany). The gene specific primers for the real - time PCR (RT-PCR) are as follows: $t n f-\alpha$ - forward: 5'-GGCAGGTCTACTTTGGAGTCATTGC-3', reverse: 5' ACATTCGAGGCTCCAGTGAATTCGG 3', hprt (hypoxanthine phosphoribosyltransferase) forward: 5'-ATC AGTCAACGGGGGACATA-3', reverse: 5'-AGAGGTCC TTTTCACCAGCA-3', hif-2 $\alpha$ - forward: 5'-AAGCTC CTGTCCTCAGTCTG-3', hif-2 $\alpha$ reverse: 5'-CATCCTC ATGAAGAAGTCAC-3', $p d h 3$ forward: 5'-GCTATCCA GGAAATGGGACA-3', pdh3 reverse: 5'-GGCTGGA CTTCATGTGGATT-3' ngal (lipocalin-2) forward: 5'-CA CCACGGACTACAAGTTCGC-3', 3' ngal (lipocalin-2) reverse: 5'-TCAGTTGTCAATGCATTGGTCGGTG-3', Epo forward: 5-CCACCCTGCTGCTTTTACTC-3', Epo reverse: 5'-CTTGAAGAGAACCTGGGAGT-3', iNOS (inducible nitric oxide synthase, also known as NOS2) forward: 5' AGCTGGCTCGCTTTGCCACG 3', iNOS reverse: 5' GCCTCCTTTGAGCCCTTTGT 3'; Kim1 (Kidney injury molecule 1) forward: 5' ATGAATCAGAT TCAAGTCTTC 3', Kim1 reverse: 5' TCTGGTTTGTG AGTCCATGTG 3'. All primers were purchased from Invitrogen, Darmstadt, Germany. The relative expression of the gene of interest was quantified by RT-PCR using a Q-tower thermocycler (Analytik Jena Bio Solutions, Jena, Germany). The quantitative real-time PCR was done as previously described The expression of the gene of interest was normalized to the expression of hprt and the relative expression ratio was quantified by $\Delta \Delta \mathrm{CT}$ method, where $R=2^{-\Delta \Delta C T}$ [21]. The mRNA levels in saline treated $M O R G 1^{+/+}$mice was set as 1 .

\section{Statistical analysis}

All values are presented as mean \pm standard error of mean (SEM). Statistical analyses were performed with the statistical package SigmaPlot 13 software (SYSTAT Software, San Jose, CA, USA). Results were evaluated by 
the Kruskal-Wallis One way Analyses of Variances on Ranks test, followed by the Mann-Whitney-Rank Sum-Test to analyse the differences between two groups. All Pairwise Multiple Comparison Procedures were performed with Student-Newman-Keuls Method. Survival was analysed by the Kaplan-Meier test with log-rank statistic. Differences were considered significant when $p<0.05$.

\section{Results}

\section{Reduced MORG1 expression helped prevent damage to} renal tissue after administration of LPS

It is well documented that endotoxemia causes tubular damage in murine models [22]. To assess the LPS effect on renal tissue we performed periodic acid Schiff's (PAS) staining on kidney paraffin sections. We detected a significantly $(p<0.001)$ increased tissue damage (score $2.7 \pm 0.198$ ) most prominently in the cortex, manifested by tubular dilation and vacuolisation (shown with asterisk on the images) in wild-type $M O R G 1^{+/+}$mice due to LPS administration compared with the saline treated wild-type mice (score $1.19 \pm 0.115)(p<0.001)$ (Fig. 1a, b). However, endotoxemic heterozygous $M O R G 1^{+/-}$mice showed significantly $(p=0.017)$ less dilation of proximal tubules compared with LPS treated MORG1 $1^{+/+}$mice (Fig. 1a, b). We also analysed the expression of KIM1 (Kidney injury molecule 1) in the renal sections as a marker of the early tubular damage $[23,24]$. As expected in saline treated wild-type and heterozygous $M O R G 1^{+/-}$mice, expression of KIM1 was not found, while LPS administration significantly induced the protein (Fig. 1c, d). The injured proximal tubuli showed a positive immunological stain of KIM1, localised to the apical brush border of the proximal tubular epithelial cells (Fig. 1c). We counted the number of KIM1 positive tubuli per kidney section and found that endotoxemic $M O R G 1^{+/-}$mice had $18.75 \pm 2.87$ injured proximal tubuli compared with their LPS treated wild-type littermates $65.5 \pm 5.95,(p=0.029)$. Immunohistochemistry revealed that KIM1 tubular expression was induced in both genotypes upon LPS treatment, nevertheless we detected significantly more KIM1 positive tubuli in endotoxemic wild-type $M O R G 1^{+/+}$ compared with the MORG1 $1^{+/-}$LPS treated mice (Fig. 1c, d). We next assed the Kim1 mRNA in renal tissue and found that endotoxemia induced Kim1 mRNA expression was significantly augmented in both genotypes compared with saline treated controls $p=0.004$ and $p$ $=0.003$ for $\mathrm{MORG1}^{+/+} / \mathrm{LPS}$ and $M O R G 1^{+/-} / \mathrm{LPS}$ mice, respectively. Moreover, MORG1 heterozygosity decreased significantly the Kim1 mRNA levels $(128.96 \pm 29.81$ fold $)$ then the corresponding endotoxemic wild-type littermate (369.87 \pm 57.36 fold), $(p=0.003)$ (Fig. 1e).

\section{MORG1 suppression reduced renal NGAL expression in} endotoxemic animals

We also investigated acute renal injury by determining the urinary and plasma concentrations of neutrophil gelatinase-associated lipocalin (NGAL), an early marker of AKI, in wild-type and heterozygous mice (Fig. 2). As expected we found a significantly $(p<0.001)$ increased NGAL levels in plasma due to the LPS application, in both mice genotype (Fig. 2a). Analyses of the urinary NGAL protein concentrations showed significantly higher levels in LPS treated wild-type and MORG1 heterozygous mice compared with untreated controls in both genotypes, $p<0.001$ and $p=0.002$, for $\mathrm{MORG1}^{+/+}$/ LPS and MORG1 $1^{+/-} /$LPS mice, respectively. Nevertheless, the urinary concentrations of NGAL in LPS treated $\mathrm{MORG1}^{+/-}$animals were reduced with about $44 \%$ (10.029 $\pm 1.948 \mu \mathrm{g} / \mathrm{ml}$ ) compared with the endotoxemic wild-type mice $(15.643 \pm 1.074 \mu \mathrm{g} / \mathrm{ml})$, although, the difference did not rich yet a statistical significance $(p=0.052)$ (Fig. $2 b)$. Next, we investigated the renal ngal gene expression in wild-type and Morg1 heterozygous mice by real-time PCR. We found that the untreated mice showed extremely low levels of ngal mRNA, while endotoxemia sharply induced renal ngal expression levels in both genotypes. $P$ values were correspondingly $p<0.001$ and $p=0.002$ for $M O R G 1^{+/+} /$LPS and $M O R G 1^{+/} /$LPS mice. Interestingly, we measured a significantly $(p=0.021)$ diminished $n g a$ l gene expression in $M O R G 1^{+/-} /$LPS mice $(795.070 \pm$ 76.054 fold increase) compared with $\mathrm{MORG1}^{+/+} / \mathrm{LPS}$ treated mice $(1742.007 \pm 324.135$ fold increase) (Fig. 2c). We also investigated renal function by determining the urinary albumin-creatinine-ratio (uACR) in endotoxic wild-type and heterozygous mice. The exposure to LPS induced microalbuminuria ( $\mathrm{uACR}>30 \mathrm{mg} / \mathrm{g}$ ) in both genotypes, but the $M O R G 1^{+/-}$animals showed significantly $(p<0.05)$ lower uACR compared with $M O R G 1^{+/+}$ mice upon LPS exposure (Fig. 2d). On the other hand, analyses of the plasma creatinine (Cre) (Fig. 2e) and blood urea nitrogen (BUN) (Fig. 2f) concentrations often used as well a marker of the renal function [24, 25] depicted that endotoxin application elevated Cre and BUN levels in both genotypes and the MORG1 reduced expression did not significantly influence their concentrations (Fig. 2e, f).

\section{Endotoxemia reduced the renal expression of PHD3}

Septic inflammation contributes to reduced oxygen supply and tissue hypoxia. The main cellular sensor to oxygen supply is the family of enzymes named HIF-prolylhydroxylases (PHDs) [13]. The MORG1 protein forms a complex with the PHD3 isoform, therefore we investigated whether the expression levels of PHD3 in renal tissue after LPS administration may be dependent on MORG1 reduction. Immunohistology of kidney sections showed an increased PHD3 protein expression in saline 
a

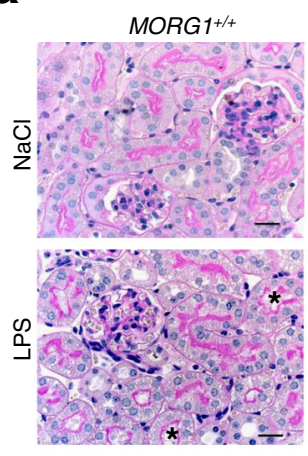

C
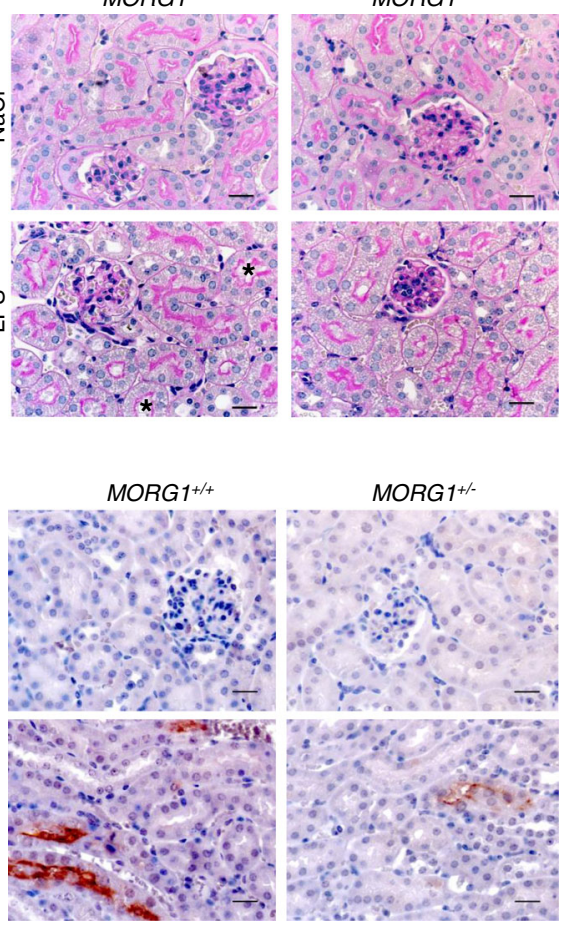

b

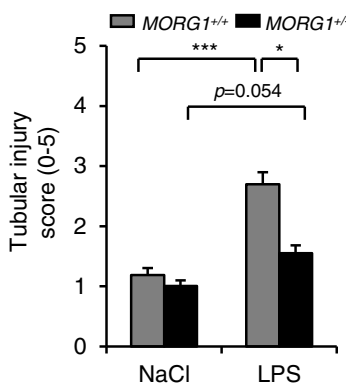

d

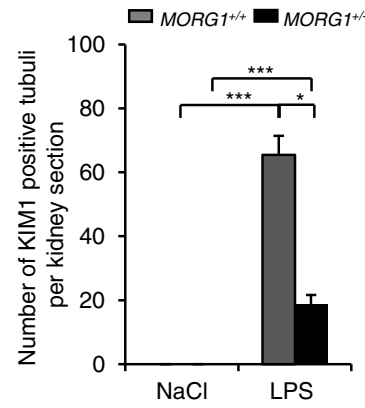

e

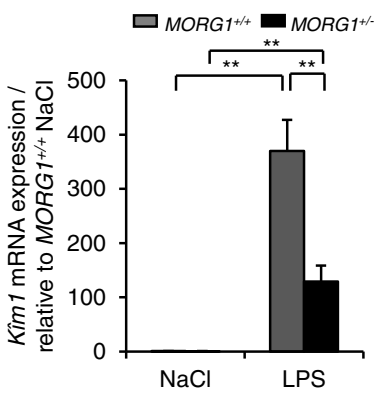

Fig. 1 a-e: Analysis of renal damage. a Detection of renal injury by PAS- staining $24 \mathrm{~h}$ post LPS administration. LPS treatment induced cortical tubular dilatation in $\mathrm{MORG}^{+/+}$mice. Representative images are shown. The vasodilation and brush border damages are shown with asterisk on the images. Original magnification 400x. Bars correspond to $20 \mu \mathrm{m} . N=6$ per group. b Semi-quantitative cortical tubular injury scores. The score ranges from 0 to 5 depending on level of tubular damage. $N=6, M O R G 1^{+/+} / L P S$ vs. MORG ${ }^{+/+}$saline treated mice, $p<0.001 ; M O R G 1^{+/+} / L P S$ vs. MORG1 ${ }^{+/-} / \mathrm{LPS}, p=0.017 .{ }^{*} p<0.05,{ }^{* * *} p<0.001$. c Detection of the tubular damage by immunohistochemical detection of the Kidney injury molecule 1 (KIM1) protein expression in renal sections $24 \mathrm{~h}$ post endotoxemia or saline treatment. Representative images are shown. Original magnification 400x. Bars $20 \mu \mathrm{m}$. N =4. d Number of KIM1 positive tubuli per kidney section are graphically presented. $N=4$ mice per group.

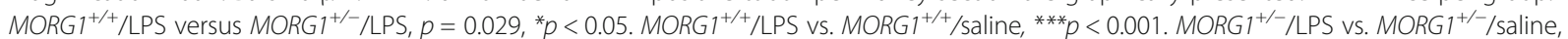
${ }^{* *} p<0.001$. e Real-time PCR analyses of the Kim1 mRNA expression in endotoxemic and saline treated wild-type and MORG $1^{+/-}$mice. LPS induced a robust increase in the Kim1 mRNA expression in both genotypes. Nevertheless, a down-regulation of MORG1 was associated with a significantly lower expression of Kiml compared with the wild-type endotoxemic mice. $\mathrm{N}=4 \mathrm{MORG1^{+/+ }} / \mathrm{NaCl} ; \mathrm{N}=8 \mathrm{MORG}{ }^{+/+} / \mathrm{LPS} ; \mathrm{N}=7 \mathrm{MORG1}$

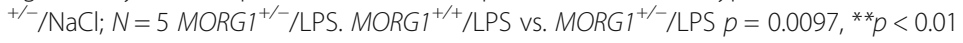

treated MORG1 ${ }^{+/+}$compared with the $M O R G 1^{+/-}$mice $(p$ $=0.006$ ) (Fig. 3a). Furthermore, LPS treatment significantly $(p<0.001)$ reduced PHD3 expression compared with the saline treated mice in both $M O R G 1^{+/+}$and $M O R G 1^{+/-}$ mice (Fig. $3 \mathrm{a}, \mathrm{b}$ ). In addition, the PHD3 positive cells per field were significantly lower $(p<0.001)$ in the endotoxemic $M O R G 1^{+/-}$mice $(80.67 \pm 3.89)$ compared with $M O R G 1^{+/+}$
LPS treated mice $(123.53 \pm 4.4)$ (Fig. 3a, b). Real-time PCR analyses of Phd 3 mRNA expression depicted a reduced basal $P h d 3$ gene expression in $M O R G 1^{+/-}$mice compared to $M O R G 1^{+/+}$mice (Fig. 3c). On the other hand, LPS administration significantly $(p<0.05)$ inhibited the $P h d 3$ mRNA expression in the $M O R G 1^{+/+}$mice, whereas we did not find significant differences in the Phd3 gene expressions 

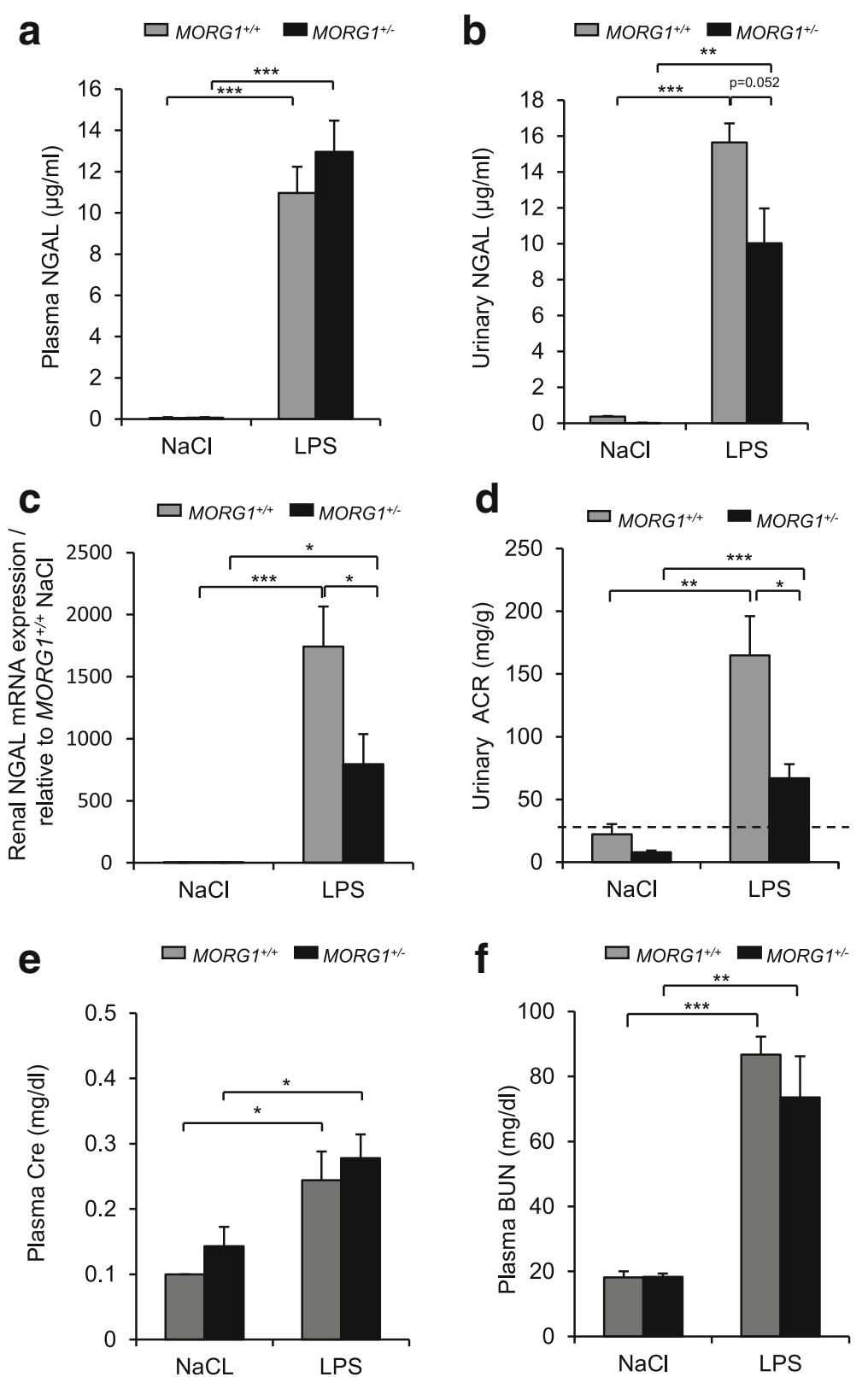

Fig. 2 a-f: Analysis of renal functional parameters $24 \mathrm{~h}$ following endotoxemia induction or saline solution application. a Determination of the plasma concentration of Neutrophil gelatinase associated lipocaline (NGAL). $N=6$ per group, ${ }^{* * *} p<0.001$. $\mathbf{b}$ Measurement of the NGAL urine

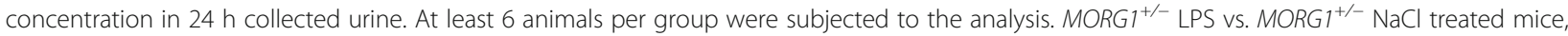
$p=0.002 ; \mathrm{MORG}^{+/+}$LPS vs. MORG1 $1^{+/+} \mathrm{NaCl}$ treated mice, $p<0.001 .{ }^{* *} p<0.01,{ }^{* * *} p<0.001$. c Determination of the renal NGAL mRNA expression

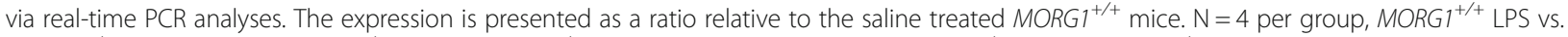
MORG $1^{+/-}$LPS, $p=0.021 ;$ MORG1 $1^{+-}$LPS vs. MORG1 ${ }^{+/-} \mathrm{NaCl}$ treated mice $p=0.049 ;$ MORG1 $^{+/+}$LPS vs. MORG1 ${ }^{+/+} \mathrm{NaCl}$ treated mice, $p<0.001 .{ }^{*} p<$ $0.05,{ }^{* * *} p<0.001$. d Detection of renal injury by determination of urinary ACR (UACR). LPS treatment significantly increased the UACR in MORG1 $1^{+/+}$ and MORG1 ${ }^{+/-}$mice compared with the corresponding controls, $p=0.008$ and $p<0.001$ respectively; the levels of uACR are significantly lower in endotoxemic MORG1 ${ }^{+/-}$mice relatively to the equally treated MORG1 ${ }^{+/+}$mice, $p=0.03$. N $=6$ per group. ${ }^{*} p<0.05$, ${ }^{* *} p<0.01,{ }^{* * *} p<0.001$. e Detection of plasma creatinine (Cre) levels $24 \mathrm{~h}$ following endotoxemia or saline application. $\mathrm{N}=7$ per group for $\mathrm{MORG1^{+/+ }}$ saline and $\mathrm{MORG} \mathrm{I}^{+/-}$ saline, $N=9$ mice per group for MORG1 $1^{+/+}$LPS and MORG1 ${ }^{+/-}$LPS. LPS induced increase in plasma Cre in both genotypes compared with the control saline treated groups. MORG1 ${ }^{+/+}$LPS vs. MORG $1^{+/+}$saline treated mice, $p=0.012$, MORG $^{+/-}$LPS vs. MORG $1^{+/-}$saline ${ }^{*} p=0.0156,{ }^{*} p<0.05$. f Detection of plasma blood urea nitrogen (BUN) concentrations $24 \mathrm{~h}$ following endotoxemia or saline application. $\mathrm{N}=7$ per group for $M O R G 1^{+/+}$

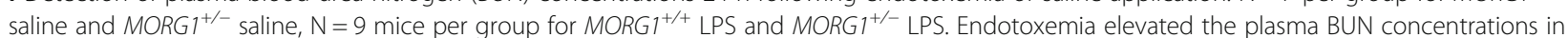

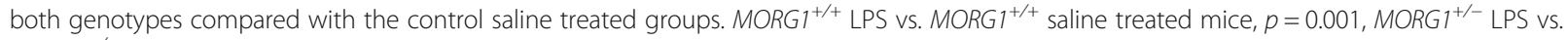
MORG1 ${ }^{+/-}$saline $p=0.004,{ }^{* *} p<0.01,{ }^{* *} p<0.001$ 

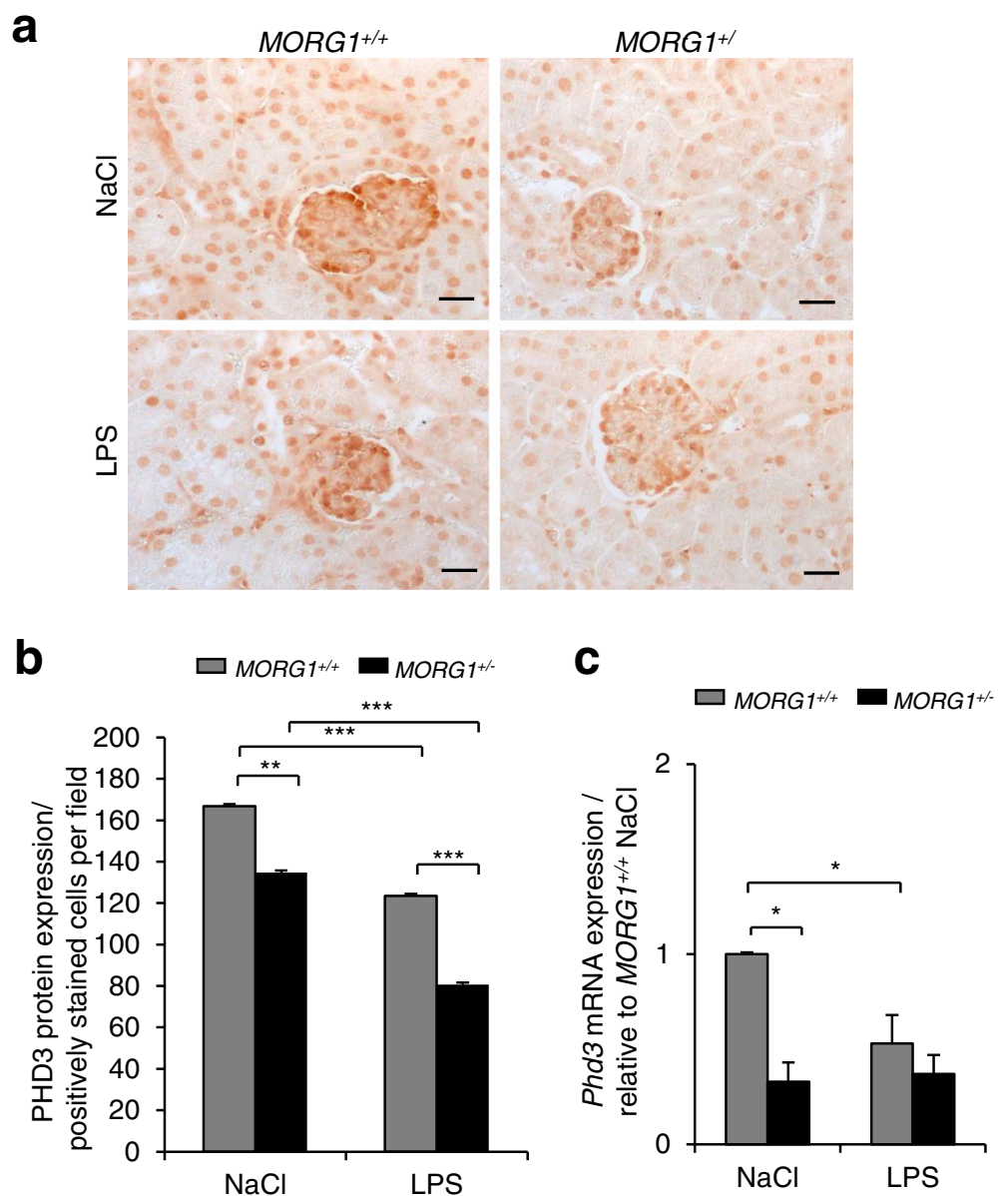

Fig. 3 a-c: PHD3 renal expression in MORG1 $1^{+/+}$and $M O R G 1^{+/-}$mice $24 \mathrm{~h}$ after LPS or NaCl application. a Immunohistological detection of renal PHD3 protein expression. Representative images are shown. Original magnification 400x. Bars correspond to $20 \mu \mathrm{m}$. b Evaluation of the PHD3 renal immunohistology. The number of the positively stained PHD3 cells per field was counted and is graphically presented. $N=4$ mice per treatment, MORG1

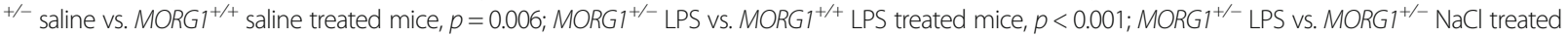
mice, $p<0.001 ;$ MORG1 ${ }^{+/+}$LPS vs. MORG1 ${ }^{+/+}$saline treated mice, $p<0.001$. ${ }^{* *} p<0.01,{ }^{* * *} p<0.001$. c Renal Phd3 mRNA expression. Real-time PCR assay revealed that MORG1 down-regulation is associated with a reduced basic expression of Phd3 mRNA. ${ }^{*} p<0.05$. LPS administration reduced Phd3 expression in $M O R G 1^{+/+}$mice but did not significantly affect $P$ hd3 expression in MORG1 heterozygous mice. $N=6$ per group, ${ }^{*} p<0.05$

between the LPS- treated and untreated $M O R G 1^{+/-}$mice (Fig. 3c).

\section{LPS administration increased renal expression of HIF-2a}

Endotoxemia increases the HIFs activation under normoxic conditions [26]. It has been shown that PHDs differentially regulate HIFs and PHD2 and 3 isoforms are mostly involved in the prolyl-hydroxylation of HIF2$\alpha[27,28]$. Thus, we next investigated the expression of HIF- $2 \alpha$ in kidney sections after LPS administration. Immunohistological studies revealed that in kidney sections of $M O R G 1^{+/-}$heterozygous animals was a higher number of HIF2- $\alpha$ positive cells per field $(99.1 \pm 3.97)$ compared with the wild-type mice $(63.5 \pm 2.99),(p<$ 0.001). LPS injection further elevated the number of the HIF2- $\alpha$ positive cells per field in renal sections in both MORG1 $^{+/+}(107.1 \pm 4.67)$ and MORG1 $1^{+/-}(139.6 \pm 5.89)$ mice relatively to the saline treated controls $(p<0.001)$ (Fig. 4a, b). Analyses of the gene expression of Hif2- $\alpha$ depicted reduced $(p=0.018)$ basal levels in MORG1 $1^{+/-}$ relatively to $M O R G 1^{+/+}$mice (Fig. 4c). We further evaluated the renal gene expression of the mainly HIF2- $\alpha$ regulated gene erythropoietin in whole renal homogenates and found that its basal and LPS-dependent induction was numerically increased in the MORG1 heterozygous animals compared to the $M O R G 1^{+/+}$mice, but did not reach statistical significance (Fig. 4 d).

\section{Heterozygous MORG $1^{+/-}$deletion is associated with reduced plasma IL-6 levels in LPS treated mice}

Since it has already been shown that plasma cytokine levels of IL-6 correlate with survival as well as endotoxin levels in patients with septic syndrome [29], we measured the plasma concentrations of IL- 6 and IFN $\gamma$. We 

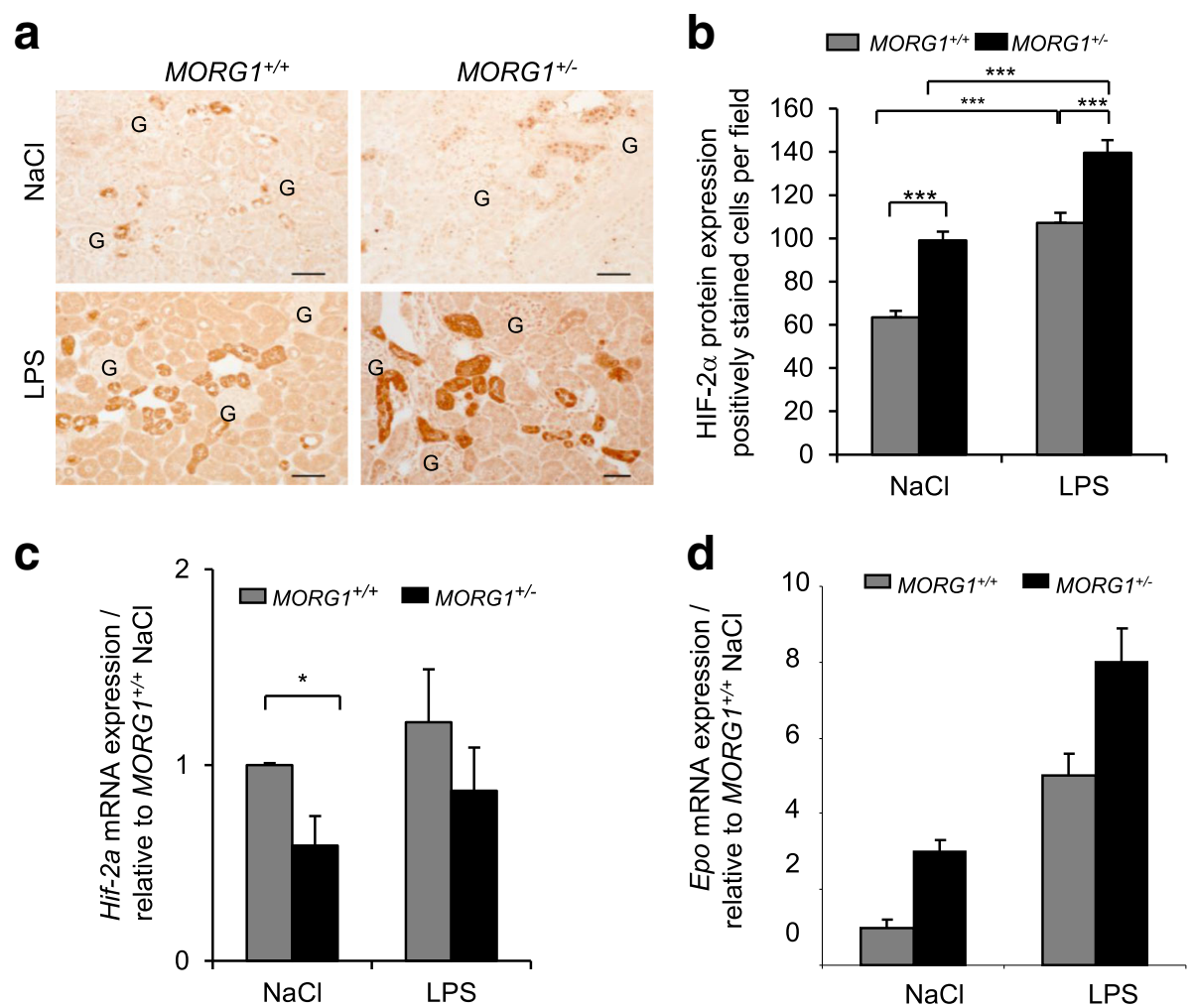

Fig. 4 a-d: HIF-2a renal expression in MORG $1^{+/+}$and MORG $1^{+/-}$mice treated with LPS. a Protein expression of HIF-2a in kidney sections. Reduction of MORG1 expression increased basal and LPS dependent on HIF-2a tubular/peritubular protein expression. Representative images are shown. Original magnification 200x. Bars correspond to $50 \mu \mathrm{m}$. G - glomerulus. b HIF2-a renal immunohistology evaluation. The number of the positively stained HIF2-a cells per field was counted and is graphically presented. $N=6$ per group, $M O R G 1^{+/+}$saline $v$ s. $M O R G 1^{+/-}$saline treated mice, $p<0.001$; for other pairwise comparison as shown on the graph the significance was $p<0.001 .{ }^{* * *} p<0.001$. c Determination of renal Hif-2a mRNA expression using realtime PCR analyses. $\mathrm{N}=6$ per group, $M O R G 1^{+/+} \mathrm{NaCl}$ vs. MORG1 ${ }^{+/-} \mathrm{NaCl}, p=0.018$. ${ }^{*} p<0.05$. d Real-time PCR analyses of erythropoietin (Epo) kidney mRNA expression during endotoxemia. The renal expression of Epo was analysed as a representative HIF-target gene. The basal levels of Epo were slightly, but not significantly increased in $M O R G 1^{+-}$mice. $\mathrm{N}=6$ per group

found that LPS administration sharply elevated the plasma levels of IL-6 $(p<0.05)$ in $M O R G 1^{+/+}$mice (Fig. 5a) as previously shown [29]. However, the IL-6 plasma concentrations in endotoxemic $M O R G 1^{+/-}$mice were significantly $(p<0.05)$ lower than in $M O R G 1^{+/+}$ mice (Fig. 5a). In contrast, plasma concentrations of IFN $\gamma$ were enhanced by LPS administration in both genotypes (Fig. 5b).

\section{LPS-induced renal TNF- $a$ expression is significantly reduced in $\mathrm{MORG} 1^{+/-}$mice}

An important indicator of renal inflammation is the local expression of the pro-inflammatory cytokine tumour necrosis factor alpha (TNF- $\alpha$ ). Therefore, we investigated the protein and gene expression of TNF- $\alpha$ in renal tissue lysates after exposure to LPS. The renal mRNA expression of Tnf- $\alpha$ was strongly up-regulated in $M O R G 1^{+/+}$and $M O R G 1^{+/-}$mice 24 h post LPS administration, relative to the corresponding controls. However, we found a significantly $(p=0.003)$ lower Tnf- $\alpha$ mRNA level in $M O R G 1^{+/-}$mice after LPS application (Fig. 6a) in comparison to the endotoxemic $M O R G 1^{+/+}$litter-mates (Fig. 6a). Furthermore, Western blot analysis revealed that LPS significantly $(p=0.008)$ elevated as well the renal protein expression of TNF- $\alpha$ in $M O R G 1^{+/+}$mice, compared with untreated mice (Fig. 6b, c). However, the TNF$\alpha$ protein levels were significantly $(p=0.004)$ reduced in $M O R G 1^{+/-}$heterozygous mice exposed to LPS in comparison to their endotoxemic $M O R G 1^{+/+}$litter-mates (Fig. 6b, c).

\section{MORG1 suppression affects NF-KB signaling}

Since IL-6 plasma levels and TNF- $\alpha$ renal expression were reduced in endotoxemic $M O R G 1^{+-}$animals after LPS application, despite the increased HIF- $2 \alpha$ accumulation in renal tissue and as both are also regulated by the transcriptional activity of the nuclear factor-kappa B $(\mathrm{NF}-\mathrm{kB})$, we additionally assessed the activation of NF- $\kappa B$ by analysing the phosphorylation rate of the inhibitor of $\kappa B(\mathrm{I} \kappa \mathrm{B}-\alpha)$ by Western blot. We detected an LPS-dependent significant $(p=0.048)$ elevation of phospho-IкB- $\alpha$ (pIкB- $\alpha$ ) levels in the $M O R G 1^{+/+}$mice 

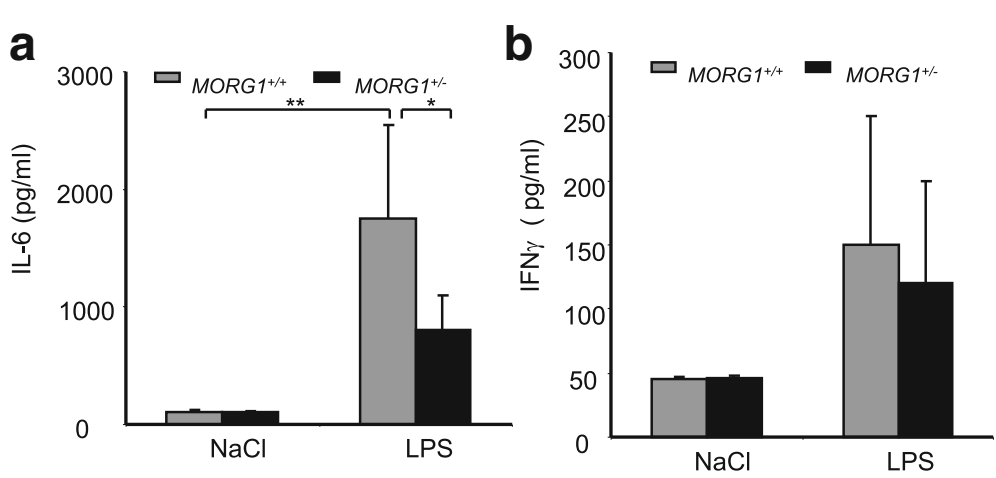

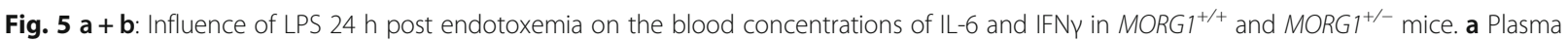
concentration of IL-6. LPS administration elevates significantly the IL-6 plasma levels in MORG1 ${ }^{+/+}$animals. Systemic IL-6 levels are reduced in LPS treated $M O R G 1^{+/-}$mice in comparison to MORG $1^{+/+} / L P S$ mice. $N=6$ per group. ${ }^{*} p<0.05,{ }^{* *} p<0.01$. b LPS treatment did not affect the IFNY plasma levels in $M O R G 1^{+/-}$mice compared with $M O R G 1^{+/+}$mice indicating that the suppression of IL-6 is not an unspecific effect. $N=6$ per group

compared to the MORG1 ${ }^{+/-}$LPS exposed mice (Fig.7a, b). Supporting this observation, the levels of the IкB- $\alpha$ protein were reduced in the protein lysates with higher $\mathrm{pI \kappa} B-\alpha$ content as a likely result of the IкB- $\alpha$ proteasomal degradation. Moreover, analyses of the IKK-phosphorylation, the upstream kinase involved in the phosphorylaton of the IKB- $\alpha$, further confirmed that LPS administration elevated the levels of phospho-IKK $\alpha, \beta$ in the MORG1 $1^{+/+}(p<0.01)$ but not in the $M O R G 1^{+/-}$animals (Fig. 7c, d). We further explored NF$\kappa B$ activation by examining protein amounts of NF- $\kappa B$ in the nuclear fraction of the kidney lysates. The protein levels of NF- $\mathrm{KB}$ were increased in the LPS-treated $M O R G 1^{+/+}$mice compared with the endotoxemic $M O R G 1^{+/-}$litter-mates $(p=0.002)$ (Fig. 7e, f). Moreover, we assayed the mRNA expression of the NF- $\mathrm{kB}$ target gene $i N O S$ (inducible nitric oxide synthase) and our results showed a significantly lower expression of iNOS mRNA in the MORG1 $1^{+/}$LPS treated mice compared with the wild-type endotoxemic mice (see Additional file 1: Figure S1), thus supporting the reduced NF-kB activation in endotoxin treated $M O R G 1^{+/-}$mice.

\section{Septic $M O R G 1^{+/-}$mice are protected from inflammatory T-cell infiltration and apoptosis}

To examine further the effects of reduced MORG1 on renal inflammation, we assessed the renal infiltration of inflammatory $\mathrm{CD}^{+}$positive T-cells $24 \mathrm{~h}$ post LPS application via immunohistochemistry. We observed significantly $(p<0.001)$ less CD3 immunoreactive cells in kidney sections of the LPS exposed $M O R G 1^{+/-}$mice compared with identically treated $M O R G 1^{+/+}$animals (Fig. 8a, b). Activated, cleaved caspase-3, was investigated by Western blot from whole kidney protein lysate. Endotoxemia induced a significantly $(p=0.002)$ higher caspase-3 cleavage in wild-type mice then in saline injected wild-type mice. In contrary, reduced expression of MORG1 in heterozygous mice attenuated the renal caspase- 3 activity. We detected a significantly $(p=0.004)$ less active caspase- 3 in renal lysates of endotoxemic $M O R G 1^{+/-}$compared with $M O R G 1^{+/+}$mice injected with LPS (Fig. 8c, d).

\section{Survival is improved in septic MORG $1^{+/-}$mice}

Finally, we studied mice survival in both genotypes subsequent to LPS injection. Mice were inspected every 6-h over a 72-h period. The assay was essential to the study since the $M O R G 1^{+/-}$mice were never subjected to survival analyses before. The health status of the animals was evaluated by assessment of the Clinical Severity Score (CSS) [18]. The CSS during the survival analyses of the LPS treated mice is presented in Additional file 2: Table S1 for wild-type $\mathrm{MORG1}^{+/+}$and in Additional file 3: Table S2 for the heterozygous $M O R G 1^{+/-}$mice (see Additional files 2 and 3 respectively). The control groups from both genotypes injected with saline did not show signs of illness. For all of them the CSS was equal to 1 during the overall $72 \mathrm{~h}$ period of the survival analyses therefore the data are not presented as tables. The CSS analyses during the survival study revealed that the endotoxemic $M O R G 1^{+/-}$mice are significantly more healthy than the equally treated wild-type $M O R G 1^{+/+}$ litter-mates (see Additional file 4: Figure S2). In agreement with these findings and the less impaired renal morphology and overall reduced inflammation found in the LPS-challenged $M O R G 1^{+/-}$mice, all septic MORG1 +/- mice survived the 72-h LPS exposure (Fig. 9). On the other hand up to $20 \%$ of the wild-type $M O R G 1^{+/+}$mice died after LPS treatment (Fig. 9).

\section{Discussion}

Suppression of inflammation and improvement of tissue hypoxia are important factors to reduce organ injury [30]. Accelerated renal hypoxia is a key factor in the 


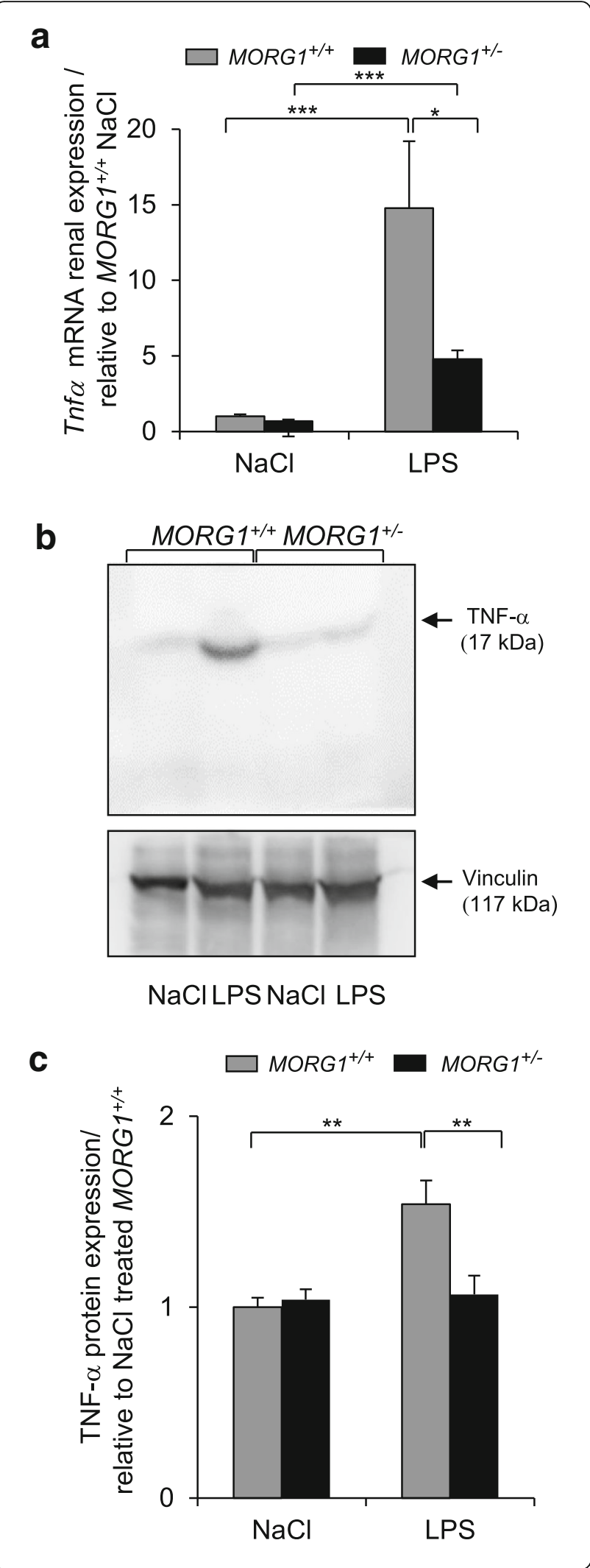

Fig. 6 a-c: Tnfa mRNA expression in renal tissue. a Influence of LPS on renal expression of Tnfa mRNA in MORG1 $1^{+/+}$and $M O R G 1^{+/-}$mice was analysed by real-time PCR $24 \mathrm{~h}$ post LPS application. $\mathrm{N}=6$,

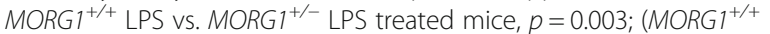
LPS vs. MORG1 $1^{+/+}$saline treated mice, $\left.p<0.001\right), M O R G 1^{+-}$LPS vs. MORG1 $1^{+/-}$saline treated mice, $p<0.001 .{ }^{* *} p<0.01,{ }^{* * *} p<0.001$. b Detection of the protein expression of TNF-a by Western blotting using whole kidney protein lysates. The protein expression of TNF-a in LPS treated MORG1 ${ }^{+/-}$mice was significantly lower than in endotoxemia- exposed $M O R G 1^{+/+}$mice. Representative images are shown. Four independent experiments were conducted. $N=$ 4. c The expression of the proteins was quantified with ImageJ. TNF-a expression levels were normalized to vinculin loading and are graphically presented relative to $\mathrm{NaCl}$ treated $\mathrm{MORG1^{+/+ }}$ mice. $\mathrm{N}=4$ per group, MORG1 $1^{+/+}$LPS vs. MORG1 ${ }^{+/+}$saline treated mice, $p=0.008 ; M O R G 1^{+/+}$LPS vs. MORG1 ${ }^{+/-}$LPS treated mice, $p=0.004 .{ }^{* *} p<0.01$

renal pathogenesis of AKI. Bacterial infection and local hypoxia oft co-exist in acute and chronic clinical conditions resulting in adverse clinical outcomes [31]. Hypoxia-inducible factors (HIFs) are the main transcription factors that regulate adaptive responses against hypoxia by activation of the expression of several target genes [32]. HIFs are rapidly eliminated in normoxic conditions due to the prolyl-hydroxylation activity of the PHDs. Yet, during hypoxia the enzymatic activity of PHDs is suppressed due to low oxygen levels leading to subsequent stabilisation and activation of HIFs [13]. There is a growing body of research demonstrating the beneficial effects of pharmacological HIF activation $[7,8,33-35]$ or administration of the proteins which are generated due to HIF target gene expression such as EPO [9, 36] and VEGF. Yet, studies have consistently shown the complexity in determining the most optimal timing for application of HIF inhibitors. HIF inhibitors have also been associated with elevated mortality rates and are known to have severe side-effects, despite reducing renal inflammation and improving renal function in sepsis [8]. We and others have previously shown that the MAPK organizer protein 1 (MORG1) plays a scaffold function by accommodation and coordination of multiple proteins from different cellular networks, related to the MAPK [10] and/or PHD3/HIF axes [11]. The exact mechanism by which MORG1 interacts with all these molecules and coordinates their function is currently incompletely understood. Recent research in our laboratory has shown that MORG1 heterozygous deficiency is renoprotective in a model of renal ischemia/reperfusion due to an elevated expression of HIF [12], or partially attenuated ischemic brain injury [37] in a model of focal cerebral ischemia. Moreover, $M O R G 1^{+/-}$mice have attenuated renal damage in a model of short-time induced hypoxia in mice [14]. In this regard in the present study we focussed on the question whether a reduced MORG1 expression/ increased HIF stabilisation could potentially aid in preventing inflammation related renal injury. We 

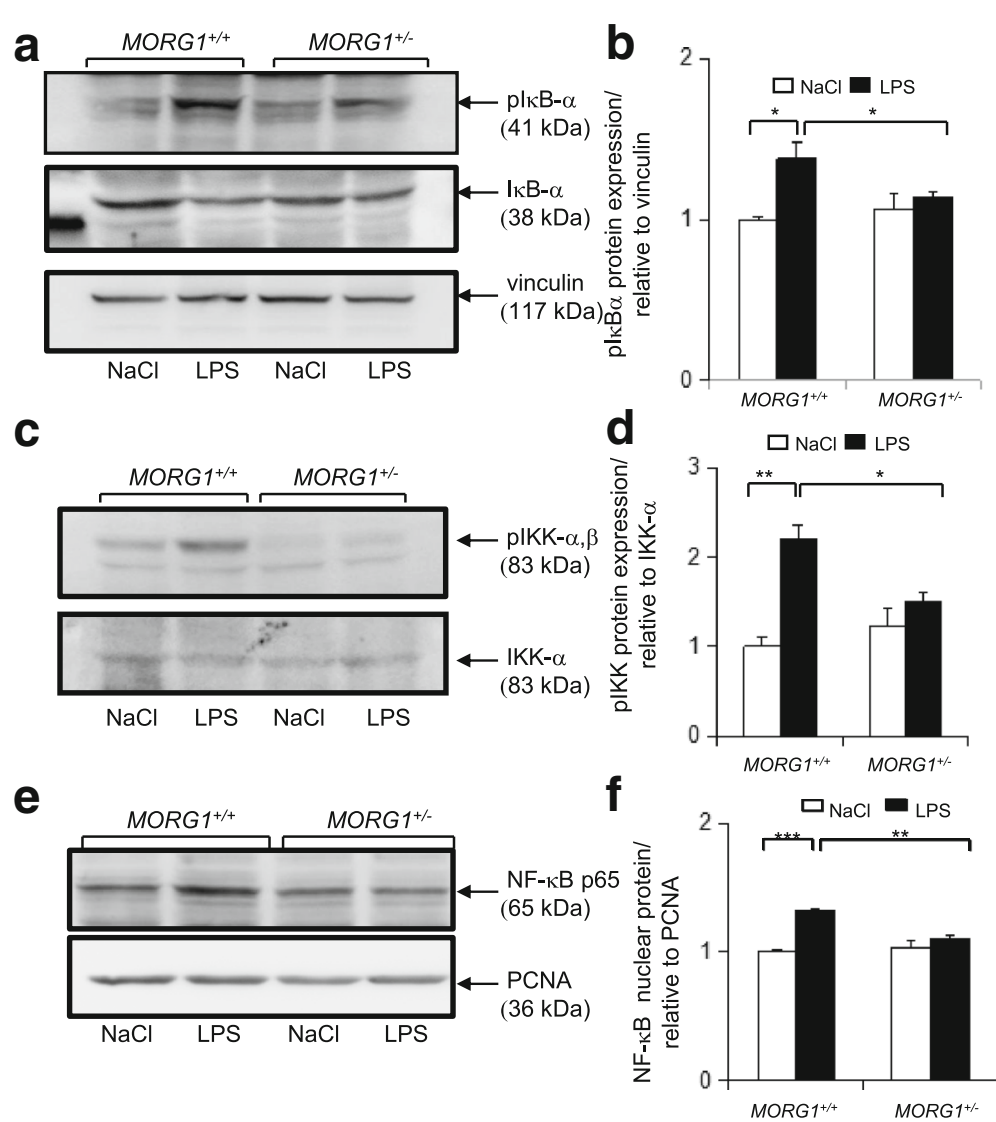

Fig. 7 a-f: Analyses of NF-kB signalling in endotoxemia mice. a Assessment of IkB-a phosphorylation in renal tissue $24 \mathrm{~h}$ after induction of endotoxemia or saline. Phospho-IKB-a levels in total kidney protein lysate were detected by Western blot analyses. The expression of IkB-a is also shown. Equal loading was detected by analyses of the vinculin protein expression. Representative images are shown. Four independent experiments were performed. $\mathbf{b}$ The expression of the proteins was analysed by ImageJ software. plkB-a expression levels were normalised to vinculin loading and

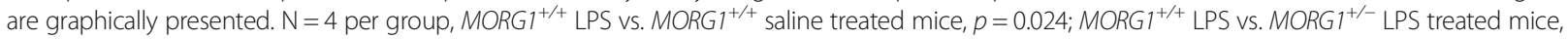
$p=0.048 .{ }^{*} p<0.05$. c Detection of IKKa, $\beta$ phosphorylation in renal tissue. Phospho-IKK-a, $\beta$ levels in total kidney protein lysate was detected by Western blot. Equal loading was monitored by detection of the vinculin protein expression. Representative images are shown. $N=4$. $\mathbf{d}$ The expression of the proteins was analysed by ImageJ software. pIKK-a, $\beta$ expression levels were normalized to IKK-a expression and are graphically presented relative to

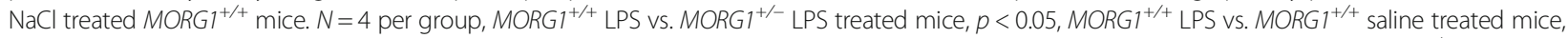
$p<0.01 .{ }^{*} p<0.05$, ${ }^{* *} p<0.01$. e Detection of NF-KB (p65) protein in the nuclear fraction of kidney lysates of $\mathrm{NaCl}$ and LPS injected MORG1 ${ }^{+/+}$and $M O R G 1^{+/-}$mice by Western blot. Equal loading was monitored by assessment of the PCNA nuclear protein expression. Representative images are shown. Three independent experiments were performed. $N=3$. $\mathbf{f}$ The expression of the proteins was analysed by ImageJ software. NF-kB nuclear levels were normalised to PCNA expression and are graphically presented relative to $\mathrm{NaCl}$ treated MORG1 $1^{+/+}$mice. $\mathrm{N}=3$ per group, MORG1 $1^{+/+} \mathrm{LPS} \mathrm{vs}$. MORG $1^{+/-}$LPS treated mice $p=0.002 ; M O R G 1^{+/+}$LPS vs. MORG1 $1^{+/+}$saline treated mice, $p<0.001 .{ }^{* *} p<0.01,{ }^{* * *} p<0.001$

utilised the well-established murine model of LPS-induced endotoxemia. In agreement with previous reports, we found that LPS administration in wild-type mice induced renal damage, mainly localized in the cortex and manifested by an increased tubular dilatation $[9,38,39]$. Although the application of $5 \mathrm{mg} / \mathrm{kg}$ BW LPS induced a mild, but not severe damage, as higher doses of LPS administration, we detected nephrotoxicity (tubular damage characterised with an induced KIM1 expression in the injured proximal tubili), although it was not so obvious as in other models [8]. On the other hand, LPS-treated $M O R G 1^{+/-}$heterozygous mice were clearly protected from tubular damage, showed a lower KIM1 tubular immunoreactivity, revealed less proteinuria and NGAL renal expression. We have to admit that although, our experimental data showed a significant histological improvement of the renal tissues in endotoxemic MORG1 ${ }^{+/-}$mice relatively to the wild-type $M O R G 1^{+/+}$LPS treated animals, there were still increased levels of plasma BUN in both genotypes. This discrepancy could be due to the lower sensitivity of the heterozygous mice to LPS induced nephrotoxicity, which also reflected the lower renal inflammation (a conclusion that seems not likely because $M O R G 1^{+/-}$mice are not totally protected from damage). We believe that other extrarenal factors such as volume status, catabolism may have affected the plasma BUN 


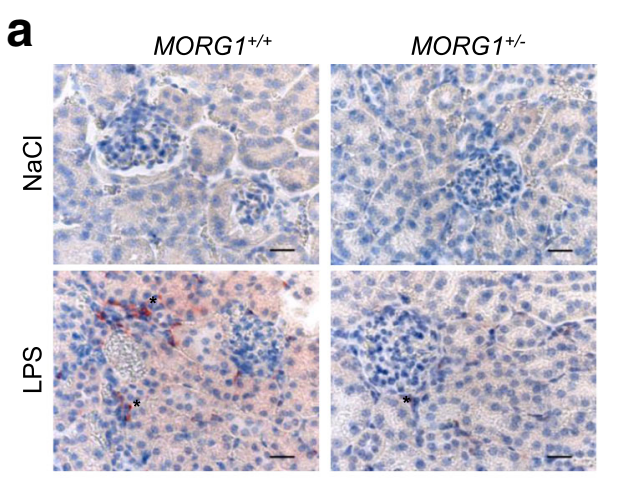

C $M O R G 1^{+/+} M O R G 1^{+/}$

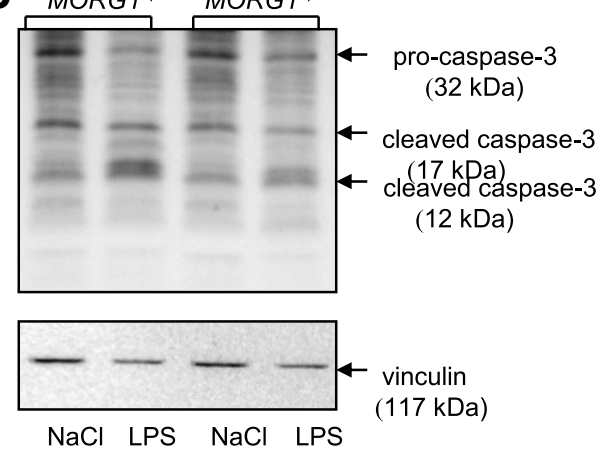

b

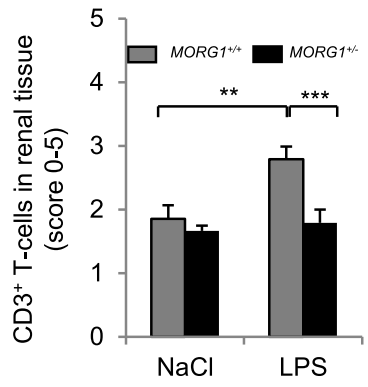

d

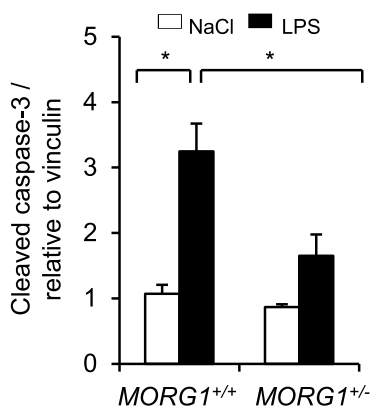

Fig. 8 a-d: Reduced MORG1 expression ameliorates the peritubular infiltration of inflammatory T-cells in renal tissue and reduced renal caspae-3 cleavage in endotoxemic mice $24 \mathrm{~h}$ post LPS application. a Immunohistological detection of $\mathrm{CD}^{+}$cells. Representative images are shown. The $\mathrm{CD}^{+}$cells are shown with asterisk on the images. The nuclei were counter-stained with DAPI. The Original magnification 400x. Bars correspond

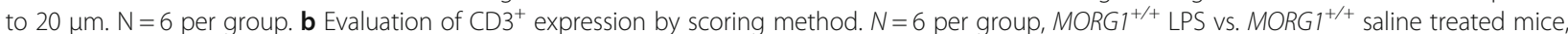
$p=0.003 ; M_{\text {MORG }}{ }^{+/+}$LPS vs. MORG1 ${ }^{+/-}$LPS treated mice, $p<0.001 .{ }^{* *} p<0.01,{ }^{* * *} p<0.001$. c Analysis of caspase-3 activation by Western blot in kidney lysates cytosolic fraction of $\mathrm{NaCl}$ and LPS injected $M O R G 1^{+/+}$and $M O R G 1^{+/-}$animals. Activation of caspase-3 was revealed by the presence of the 17 and $12 \mathrm{kDa}$ protein bands, corresponding to the cleaved (activated) caspase-3. Equal loading was controlled by vinculin expression. Representative images from three independent experiments are shown. $N=3$. $\mathbf{d}$ The proteins levels of cleaved caspase-3 were measured by ImageJ software, normalized to vinculin expression and are graphically presented relative to $\mathrm{NaCl}$ treated $M O R G 1^{+/+}$mice. $N=3$ per group, MORG1 ${ }^{+/+}$LPS vs. MORG1 ${ }^{+/+}$saline treated mice, $p=0.002 ;$ MORG1 ${ }^{+/+}$LPS Vs. MORG $1^{+/-}$LPS treated mice, $p=0.004 .{ }^{* *} p<0.01,{ }^{* * *} p<0.001$

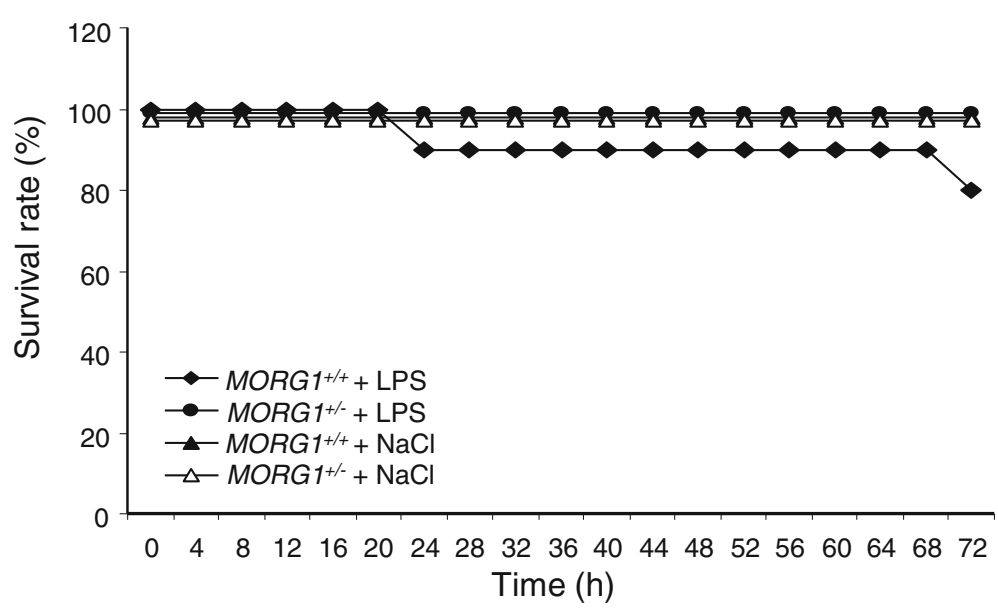

Fig. 9 Survival studies. The animals were randomly separated into 4 groups: MORGI ${ }^{+/+}$and $M O R G 1^{+/-}$injected with $0.9 \% \mathrm{NaCl}$, and $\mathrm{MORG} 1^{+/+}$ and MORG ${ }^{+/-}$injected with $5 \mathrm{mg} / \mathrm{kg}$ BW LPS. The survival rate was analysed over a period of $72 \mathrm{~h} .10$ mice per group were approved by the Local Animal Committee of Thuringia and were subjected to the survival analyses. The survival rate in MORG1 $1^{+/+}$animals treated with LPS was reduced by $20 \%$ compared with the $\mathrm{NaCl}$ controls, whereas all MORG1 ${ }^{+/-}$mice injected with LPS survived the $72-\mathrm{h}$ observation period 
levels. More detailed studies including more parameters for assessment of the renal function at different timepoints are necessary to proof whether the clearly observed improvement in histological injury may ultimately be also seen functionally.

The improved histological renal injury could be also related to an elevated HIF- $2 \alpha$ protein expression in tubules (not only in nuclei, but also in the cytoplasm), which was associated with a reduced basal PHD3 protein expression in the $M O R G 1^{+/-}$compared to $M O R G 1^{+/+}$ mice. LPS application further attenuated the PHD3 expression in renal tissue $24 \mathrm{~h}$ post endotoxemia induction in both genotypes.

Several studies have reported that PHD3 is a HIF-2 $\alpha$ target gene, therefore one could expect an up-regulation of PHD3 in the renal tissues when HIF- $2 \alpha$ levels are elevated, it is possible that we did not detect this because it will happen in a later time in the renal tissue. Or it is possible that in those conditions PHD3 is regulated via HIF- $\alpha$ independent mechanism. Furthermore, our data confirmed that endotoxemia increased the plasma levels of the pro-inflammatory cytokine IL- 6 in plasma and the TNF- $\alpha$ renal expression in wild type $M O R G 1^{+/+}$mice $[29,40]$ while in contrast IL- 6 and TNF- $\alpha$ induction were significantly reduced in $M O R G 1^{+-}$mice. This finding open the question whether MORG1 heterozygosity could play a role not only in the HIFs pathway, but as well in the NF- $\mathrm{KB}$ signalling path, that is activated through LPS/ TLR4 signalling. Upon LPS or TNF- $\alpha$ stimulation NF-kB is activated in an IKK $\alpha, \beta$, depended manner, which phosphorylates $\mathrm{I} \kappa \mathrm{B}-\alpha$ leading to proteasomal degradation of IKB- $\alpha$ and subsequent liberation, nuclear translocation and activation of the NF- $\kappa B$ complex [41-43]. Indeed, we were able to detect an intact NF- $\mathrm{kB}$ signalling path in wild-type LPS treated $M O R G 1^{+/+}$mice, characterised with an increased phosphorylation levels of IкB- $\alpha$ and IKK $\alpha, \beta$, as well as elevated NF- $\kappa B$ nuclear translocation and increased $i N O S$ expression. Intriguingly, in endotoxemic $M O R G 1^{+/-}$mice the NF- $\mathrm{kB}$ signalling was impaired as the phosphorylation levels of IKB- $\alpha$ and IKK $\alpha, \beta$ were significantly inhibited in endotoxemic $M O R G 1^{+/-}$mice, compared with the wild-type LPS treated mice, similarly NF- $k B$ activity was inhibited as revealed by the reduced $i N O S$ mRNA production. What causes these effects in endotoxin treated $M O R G 1^{+/-}$mice? An alternative interpretation of the data could be that MORG1 heterozygous mice are less sensitive to the LPS induced nephrotoxicity, which could be associated with lower levels of TLR4 in those animals leading to reduced inflammation and an inhibition of the NF- $\mathrm{kB}$ signalling path compared with the wild-type endotoxemic mice. WE are currently further study this possibility, but have not answer yet. Furthermore, a recent finding of the Huh, $\mathrm{H}$. et al. [44] reporting a scaffolding role of STRAP (Serine-threonine kinase receptor associated protein) for NF- $\mathrm{B}$ [44]. Interestingly, STRAP is a scaffold protein, which as MORG1 belongs to the WD-40 repeats proteins and its depletion shows striking similarities with our data in regard to NF- $\mathrm{kB}$ regulation.

In addition, the observed anti-inflammatory effect of MORG1 down-regulation could be also related to a reduced vasodilataion and hypotension in MORG1 endotoxemic mice. Although we did not performed experiments to test this opportunity it was shown in LPS treated rats that a reduction of NF- $\mathrm{kB}$ signalling path was associated with an increased vasoconstriction in mice $[45,46]$.

One the other hand, a role of PHD3 in controlling the NF- $K B$ signalling through inhibition of IKK $\beta$ phosphorylation, independent of PHD3 hydroxylation activity was suggested [47]. Our data also confirm this novel molecular link. These mechanisms most likely play a role in fine-tuning the regulation and coordination of HIFs (hypoxia) and NF- $\mathrm{kB}$ (inflammation) in the cell, involving MORG1 in a scaffolding function in the PHD3 and NF-kB complexes. As the LPS-treated mice in our experiments demonstrated a reduced expression of MORG1 (only) in the heterozygous $M O R G 1^{+/-}$mice, perhaps this strongly suggests that MORG1 may be a new piece of the NF- $\mathrm{kB}$ puzzle. Reduced inflammation in $M O R G 1^{+/-}$endotoxemic mice is/may also related to an inhibition of the NF- $\mathrm{kB}$ signalling complex. These $M O R G 1^{+/-}$anti-inflammatory effects observed in endotexemia are uncoupled from the plasma accumulation of NGAL or INFy, where no differences were found between both genotypes after administration of LPS. On the other hand, we found that the renal expression of ngal and the urinary levels of NGAL were reduced in MORG1 heterozygous mice that underwent endotoxemia treatment. Thus, the plasma NGAL protein could be a result of other organ damage and a response to a systemic effect due to inflammation, than an early marker of the renal injury. Moreover, it is difficult to use as an early marker, protein which is almost not produced in the healthy mice and humans, thus there is not a good comparison start point for the analyses.

Thus, modulation of MORG1 scaffolding function or expression, according to our data, may offer a very promising therapeutic target to help prevent acute renal injury.

\section{Conclusions}

Our findings suggest that a modulation of the MORG1 expression ameliorates histological renal damage and has anti-inflammatory effects in a murine endotoxemia model through modulation of HIF stabilisation and/or simultaneous inhibition of the NF- $\mathrm{KB}$ signalling. The exact mechanism(s) of how MORG1 regulates the interplay between HIFs and NF- $\mathrm{KB}$ paths need further 
studies. Thus, here for the first time we show that MORG1 scaffold could represent an important link between innate immunity and inflammation, a finding which could be of therapeutic interest to attenuate acute renal damage related to sepsis or other inflammatory renal diseases.

\section{Additional files}

Additional file 1: Figure S1. iNOS mRNA expression in endotoxemic renal tissue. Real-time PCR was performed using total kidney CDNA from saline or LPS treated wild-type respectively MORG1 heterozygous mice. The animals underwent LPS or saline treatment for $24 \mathrm{~h}$. The application of LPS significantly induced the renal iNOS (inducible Nitric Oxide Synthase) gene expression in both genotypes. While endotoxemic wild-type mice were characterised with a robust expression of $i N O S$, the MORG $1^{+/-}$mice showed only a mild activation of the iNOS expression. The mRNA expression ratio is presented in folds relative to the wild-type $\mathrm{NaCl}$ treated mice. MORG $1^{+/-} /$LPS mice v.s. MORG $1^{+/+} /$LPS mice, ${ }^{* * *} p<0.001$. NaCl treated $M O R G 1^{+/+}$mice v.s. MORG $1^{+/+} \Lambda P S$ mice, ${ }^{* *} p=0.006$. NaCl treated MORG ${ }^{+/-}$mice v.s MORG $1^{+/-} /$LPS mice, ${ }^{* *} p=0.006 . N=4$ mice per group for wild-type and $M O R G 1^{+/-} \mathrm{NaCl}$ treated mice; $N=7$ mice per group for $M O R G 1^{+/+} / \mathrm{LPS}$ and $M O R G 1^{+/-} /$LPS mice. Data are presented as mean \pm SEM. (PPTX $68 \mathrm{~kb}$ )

Additional file 2: Table S1. Evaluation of the animal well-being during the survival analyses of the wild-type MORG ${ }^{+/+}$mice treated with LPS by Clinical Severity Score. 10 animals were subjected to the survival analyses and were monitored every $4 \mathrm{~h}$ during the $72 \mathrm{~h}$ survival analyses. The CSS for each individual animal subjected to the survival analyses is presented in the table. The score 5 means death of the animal and is marked with asterisk on the table. (PPTX $69 \mathrm{~kb}$ )

Additional file 3: Table S2. Evaluation of the animal well-being during the survival analyses of the heterozygous MORG1 $1^{+/}$mice treated with LPS by Clinical Severity Score. 10 animals were subjected to the survival analyses and were monitored every $4 \mathrm{~h}$ during the $72 \mathrm{~h}$ survival analyses. The CSS for each individual animal subjected to the survival analyses is presented in the table. All animals survived the $72 \mathrm{~h}$ observation period. (PPTX $69 \mathrm{~kb}$ )

Additional file 4: Figure S2. Graphical presentation of the Clinical Severity Score (CSS) of the four experimental groups subjected to survival analyses. 10 mice per group were monitored every $4 \mathrm{~h}$ during the $72 \mathrm{~h}$ survival analyses. The CSS assessment depicted that the endotoxemic wild-type animals have a reduced clinical health compared with the MORG $1^{+/-} /$LPS mice. MORG $1^{+/+} / \mathrm{NaCl}$ mice v.S. MORG $1^{+/+} / \mathrm{LPS}$ mice, ${ }^{* * *} p$ $<0.001 ; M O R G 1^{+/-} / \mathrm{NaCl}$ mice v.s. MORG1 ${ }^{+/-} /$LPS mice, ${ }^{* * *} p<0.001$; MORG $1^{+/-} /$LPS mice v.s. MORG ${ }^{+/+} /$LPS mice, ${ }^{*} p=0.017$. The data are presented as mean \pm SEM. (PPTX $63 \mathrm{~kb}$ )

\section{Abbreviations}

BW: Body weight; ELISA: Enzyme-linked immunosorbent assay; HIFs: Hypoxia inducible factors; IFNY: Interferon gamma; IKKa, $\beta$ : Inhibitor of nuclear factor kappa-B kinase subunits alpha, beta; IL-6: Interleukin-6; IkBa: Nuclear factor kappa-B inhibitor alpha; LPS: Lipopolysaccharide; MAPK: Mitogen activated protein kinase; MORG1: Mitogen activated protein kinase organizer 1; NFKB: nuclear factor kappa-B; NGAL: Neutrophil gelatinase associated lipocalin; PHD3: Prolyl hydroxylase domain-containing protein 3; TNF-a: Tumour necrosis factor alpha

\section{Acknowledgments}

We are thankful to Drs. I. Löffler and M. Liebisch for the helpful discussions during the analyses of experiments.

\section{Funding}

This study was supported by grants from the German Federal Ministry of Education and Research within the Center for Sepsis Control and Care (grant 01EO1002, Project D1.3 to GW).

\section{Availability of data and materials}

The data sets used and/or analysed during the current study are available from the corresponding author on reasonable request.

\section{Authors' contributions}

$\mathrm{TB}, \mathrm{GW}$ participated in the design of the study and drafted the manuscript. CS and KS performed animal treatments and samples' collection. TB, CS and KS performed the experiments and statistical analyses. All authors reviewed and approved the final version of the manuscript.

\section{Ethics approval and consent to participate}

The animal experiments were performed according to the guidelines set by the local Animal Committee of the State of Thuringia (Thueringer Landesamt fuer Lebensmittelsicherheits und Verbraucherschutz Abt. 2, Gesundheitlicher Verbraucherschutz, Veterinaerwesen, Pharmazie, Bad Langensalza, Germany) application and approval (file numbers of the approved animal experiments 02-023/10 and 02-023/11).

\section{Consent for publication}

Not applicable

Competing interests

All authors declare they have no competing interests.

\section{Publisher's Note}

Springer Nature remains neutral with regard to jurisdictional claims in published maps and institutional affiliations.

\section{Author details}

'Department of Internal Medicine III, Jena University Hospital, Am Klinikum 1, D-07740 Jena, Germany. ${ }^{2}$ Centre for Sepsis Control and Care (CSCC), Jena University Hospital, Jena, Germany.

Received: 6 April 2017 Accepted: 21 January 2018

Published online: 05 February 2018

\section{References}

1. Bellomo R. Acute Renal Failure. Semin Resp Crit Care. 2011;32(5):639-50.

2. Schrier RW, Wang W, Poole B, Mitra A. Acute renal failure: definitions, diagnosis, pathogenesis, and therapy. J Clin Invest. 2004;114(1):5-14

3. Schrier RW, Wang W. Acute renal failure and sepsis - Reply. New Engl J Med. 2004:351(22):2348-9.

4. Baranova IN, Souza ACP, Bocharov AV, Vishnyakova TG, Hu XZ, Vaisman BL, Amar MJ, Chen ZG, Kost Y, Remaley AT, et al. Human SR-BI and SR-BII potentiate Lipopolysaccharide-induced inflammation and acute liver and kidney injury in mice. J Immunol. 2016;196(7):3135-47.

5. Bone RC. The pathogenesis of sepsis. Ann Intern Med. 1991;115(6):457-69.

6. Blouin CC, Page EL, Soucy GM, Richard DE. Hypoxic gene activation by lipopolysaccharide in macrophages: implication of hypoxia-inducible factor 1 alpha. Blood. 2004;103(3):1124-30.

7. Bernhardt WM, Campean V, Kany S, Jurgensen JS, Weidemann A, Warnecke C, Arend M, Klaus S, Gunzler V, Amann K, et al. Preconditional activation of hypoxia-inducible factors ameliorates ischemic acute renal failure. J Am Soc Nephrol. 2006;17(7):1970-8.

8. Schindler K, Bondeva T, Schindler C, Claus RA, Franke S, Wolf G. Preconditioned suppression of prolyl-hydroxylases attenuates renal injury but increases mortality in septic murine models. Nephrol Dial Transpl. 2016; 31(7):1100-13.

9. Coldewey SM, Khan Al, Kapoor A, Collino M, Rogazzo M, Brines M, Cerami A, Hall $P$, Sheaff $M$, Kieswich JE, et al. Erythropoietin attenuates acute kidney dysfunction in murine experimental sepsis by activation of the betacommon receptor. Kidney Int. 2013:84(3):482-90.

10. Vomastek T, Schaeffer HJ, Tarcsafalvi A, Smolkin ME, Bissonette EA, Weber MJ. Modular construction of a signaling scaffold: MORG1 interacts with components of the ERK cascade and links ERK signaling to specific agonists. P Natl Acad Sci USA. 2004;101(18):6981-6.

11. Hopfer U, Hopfer H, Jablonski K, Stahl RAK, Wolf G. The novel WD-repeat protein Morg1 acts as a molecular scaffold for hypoxia-inducible factor prolyl hydroxylase 3 (PHD3). J Biol Chem. 2006;281(13):8645-55. 
12. Hammerschmidt E, Loeffler I, Wolf G. Morg1 heterozygous mice are protected from acute renal ischemia-reperfusion injury. Am J Physiol-Renal. 2009;297(5):F1273-87.

13. Myllyharju J. Prolyl 4-hydroxylases, master regulators of the hypoxia response. Acta Physiol. 2013;208(2):148-65.

14. Loeffler I, Wolf G. Morg1 heterozygous deficiency ameliorates hypoxiainduced acute renal injury. Am J Physiol-Renal. 2015;308(6):F511-21.

15. Purswani MU, Eckert SJ, Arora HK, Noel GJ. Effect of ciprofloxacin on lethal and sublethal challenge with endotoxin and on early cytokine responses in a murine in vivo model. J Antimicrob Chemoth. 2002;50(1):51-8.

16. Knotek M, Rogachev B, Wang W, Ecder T, Melnikov V, Gengaro PE, Esson M, Edelstein CL, Dinarello CA, Schrier RW. Endotoxemic renal failure in mice: role of tumor necrosis factor independent of inducible nitric oxide synthase. Kidney Int. 2001;59(6):2243-9

17. Coldewey SM, Rogazzo M, Collino M, Patel NSA, Thiennermann C. Inhibition of I kappa B kinase reduces the multiple organ dysfunction caused by sepsis in the mouse. Dis Model Mech. 2013;6(4):1031-42.

18. Gonnert FA, Recknagel P, Seidel M, Jbeily N, Dahlke K, Bockmeyer CL, Winning J, Osche WL, Claus RA, Bauer M. Characteristics of clinical sepsis reflected in a reliable and reproducible rodent sepsis model. J Surg Res. 2011;170(1):E123-34

19. Liebisch M, Bondeva T, Franke S, Daniel C, Amann K, Wolf G. Activation of the receptor for advanced glycation end products induces nuclear inhibitor of protein phosphatase-1 suppression. Kidney Int. 2014;86(1):103-17.

20. Lin F, Chen ZM. Standardization of diagnostic Immunohistochemistry literature review and Geisinger experience. Arch Pathol Lab Med. 2014; 138(12):1564-77.

21. Livak KJ, Schmittgen TD. Analysis of relative gene expression data using real-time quantitative PCR and the 2(T)(-Delta Delta C) method. Methods. 2001:25(4):402-8.

22. Schrier RW, Wang W. Mechanisms of disease: acute renal failure and sepsis. New Engl J Med. 2004:351(2):159-69.

23. Ichimura T, Hung CC, Yang SA, Stevens $J$, Bonventre JV. Kidney injury molecule-1: a tissue and urinary biomarker for nephrotoxicant-induced renal injury. Am J Physiol-Renal. 2004;286(3):F552-63.

24. Edelstein CL. Biomarkers of acute kidney injury. Adv Chronic Kidney D. 2008; 15(3):222-34.

25. Basile DP, Anderson MD, Sutton TA. Pathophysiology of acute kidney injury. Compr Physiol. 2012;2(2):1303-53.

26. Peyssonnaux C, Cejudo-Martin P, Doedens A, Zinkernagel AS, Johnson RS, Nizet V. Cutting edge: essential role of hypoxia inducible factor-1 alpha in development of lipopolysaccharide-induced sepsis. J Immunol. 2007;178(12): 7516-9.

27. Appelhoff RJ, Tian YM, Raval RR, Turley H, Harris AL, Pugh CW, Ratcliffe PJ, Gleadle JM. Differential function of the prolyl hydroxylases PHD1, PHD2, and PHD3 in the regulation of hypoxia-inducible factor. J Biol Chem. 2004; 279(37):38458-65.

28. Meneses AM, Wielockx B. PHD2: from hypoxia regulation to disease progression. Hypoxia. 2016;4:53-67.

29. Casey LC, Balk RA, Bone RC. Plasma cytokine and Endotoxin levels correlate with survival in patients with the sepsis syndrome. Ann Intern Med. 1993; 119(8):771-8.

30. Heyman SN, Rosen S, Rosenberger C. Hypoxia-inducible factors and the prevention of acute organ injury. Crit Care. 2011;15(2):209.

31. Eltzschig HK, Carmeliet P. Hypoxia and inflammation REPLY. New Engl J Med. 2011;364(20):1977.

32. Haase VH. Mechanisms of hypoxia responses in renal tissue. J Am Soc Nephrol. 2013;24(4):537-41.

33. Hill P, Shukla D, Tran MGB, Aragones J, Cook HT, Carmeliet P, Maxwell PH. Inhibition of hypoxia inducible factor hydroxylases protects against renal ischemia-reperfusion injury. J Am Soc Nephrol. 2008;19(1):39-46.

34. Takeda K, Ichiki T, Narabayashi E, Inanaga K, Miyazaki R, Hashimoto T, Matsuura H, Ikeda J, Miyata T, Sunagawa K. Inhibition of Prolyl Hydroxylase domain-containing protein suppressed Lipopolysaccharide-induced TNFalpha expression. Arterioscl Throm Vas. 2009;29(12):2132-7.

35. Warnecke C, Griethe W, Weidemann A, Jurgensen JS, Willam C, Bachmann S, Ivashchenko Y, Wagner I, Frei U, Wiesener M, et al. Activation of the hypoxia-inducible factor pathway and stimulation of angiogenesis by application of prolyl hydroxylase inhibitors. FASEB J. 2003;17(6):1186.

36. Wang ZD, Schley G, Turkoglu G, Burzlaff N, Amann KU, Willam C, Eckardt KU, Bernhardt WM. The protective effect of prolyl-hydroxylase inhibition against renal ischaemia requires application prior to ischaemia but is superior to EPO treatment. Nephrol Dial Transpl. 2012:27(3):929-36.

37. Stahr A, Frahm C, Kretz A, Bondeva T, Witte OW, Wolf G. Morg1(+/-) heterozygous mice are protected from experimentally induced focal cerebral ischemia. Brain Res. 2012;1482:22-31.

38. Heyman SN, Darmon D, Goldfarb M, Bitz H, Shina A, Rosen S, Brezis M. Endotoxin-induced renal failure - I. A role for altered renal microcirculation. Exp Nephrol. 2000;8(4-5):266-74.

39. Heyman SN, Rosen S, Darmon D, Goldfarb M, Bitz H, Shina A, Brezis M. Endotoxin-induced renal failure - II. A role for tubular hypoxic damage. Exp Nephrol. 2000;8(4-5):275-82.

40. Cunningham PN, Dyanov HM, Park P, Wang J, Newell KA, Quigg RJ. Acute renal failure in endotoxemia is caused by TNF acting directly on TNF receptor-1 in kidney. J Immunol. 2002;168(11):5817-23.

41. Rius J, Guma M, Schachtrup C, Akassoglou K, Zinkernagel AS, Nizet V, Johnson RS, Haddad GG, Karin M. NF-kappa B links innate immunity to the hypoxic response through transcriptional regulation of HIF-1 alpha. Nature. 2008;453(7196):807-U809.

42. Khan Al, Coldewey SM, Patel NSA, Rogazzo M, Collino M, Yagoob MM, Radermacher P, Kapoor A, Thiemermann C. Erythropoietin attenuates cardiac dysfunction in experimental sepsis in mice via activation of the beta-common receptor. Dis Model Mech. 2013;6(4):1021-30.

43. Prince PD, Fischerman L, Toblli JE, Fraga CG, Galleano M. LPS-induced renal inflammation is prevented by (-)-epicatechin in rats. Redox Biol. 2017;11: 342-9.

44. Huh HD, Ra EA, Lee TA, Kang S, Park A, Lee E, Choi JL, Jang E, Lee JE, Lee S, et al. STRAP acts as a scaffolding protein in controlling the TLR2/4 signaling pathway. Sci Rep. 2016;6:38849. https://doi.org/10.1038/srep38849.

45. Tunctan B, Korkmaz B, Sari AN, Kacan M, Unsal D, Serin MS, Buharalioglu CK, Sahan-Firat S, Cuez T, Schunck WH, et al. 5,14-HEDGE, a 20-HETE mimetic, reverses hypotension and improves survival in a rodent model of septic shock: contribution of soluble epoxide:hydrolase, CYP2C23, MEK1/ERK1/2/ IKK beta/IKB-alpha./NF-kappa B pathway, and proinflammatory. Cytokine formation. Prostag Oth Lipid M. 2013;102:31-41.

46. Tunctan B, Korkmaz B, Sari AN, Kacan M, Unsal D, Serin MS, Buharalioglu CK, Sahan-Firat S, Cuez T, Schunck WH, et al. Contribution of iNOS/sGC/PKG pathway, COX-2, CYP4A1, and gp91(phox) to the protective effect of 5,14HEDGE, a 20-HETE mimetic, against vasodilation, hypotension, tachycardia, and inflammation in a rat model of septic shock. Nitric Oxide-Biol Ch. 2013: 33:18-41.

47. Xue J, Li XB, Jiao S, Wei Y, Wu GH, Fang J. Prolyl Hydroxylase-3 is downregulated in colorectal cancer cells and inhibits IKK beta independent of Hydroxylase activity. Gastroenterology. 2010;138(2):606-15.

\section{Submit your next manuscript to BioMed Central and we will help you at every step:}

- We accept pre-submission inquiries

- Our selector tool helps you to find the most relevant journal

- We provide round the clock customer support

- Convenient online submission

- Thorough peer review

- Inclusion in PubMed and all major indexing services

- Maximum visibility for your research

Submit your manuscript at www.biomedcentral.com/submit 